\title{
REVIEWS
}

\section{Chain-Growth Polycondensation: Living Polymerization Nature in Poly- condensation and Approach to Condensation Polymer Architecture}

\author{
Tsutomu YoKOZAWA ${ }^{* * *, \dagger}$ and Akihiro YoKOYAMA* \\ *Department of Applied Chemistry, Kanagawa University, Rokkakubashi, Kanagawa-ku, Yokohama 221-8686, Japan \\ ** "Synthesis and Control", PRESTO, Japan Science and Technology Agency (JST)
}

(Received November 7, 2003; Accepted November 25, 2003)

\begin{abstract}
In this review article, polycondensation that proceeds in a chain-growth polymerization manner ("chain-growth polycondensation") for well-defined condensation polymers are described. Our approach to chaingrowth polycondensation is (1) activation of polymer end group by substituent effects changed between monomer and polymer and (2) phase-transfer polymerization in biphase composed of monomer store phase and polymerization phase. In the approach (1), a variety of condensation polymers such as aromatic polyamides, aromatic polyesters, aromatic polyethers, poly(ether sulfone), and polythiophene with defined molecular weights and low polydispersities were obtained. Their polycondensations had all of the characteristics of living polymerization: a linear correlation between molecular weights and monomer conversion maintaining low polydispersities, and control over molecular weights by the feed ratio of monomer to initiator. Taking advantage of the nature of living polymerization in this polycondensation, we synthesized diblock copolymers of different kinds of aromatic polyamides and of aromatic polyamide and conventional polymers such as poly(ethylene glycol), polystyrene, and poly(tetrahydrofuran), as well as triblock copolymers and star polymers containing aromatic polyamide units. Some copolymers were arranged in a supramolecular self-assembly. In the approach (2), the polycondensation of solid monomer dispersed in organic solvent with a phase transfer catalyst (PTC) was carried out, where solid monomer did not react with each other, and the monomer transferred to organic solvent with PTC reacted with an initiator and the polymer end group selectively in organic solvent, to yield well-defined polyesters.

KEY WORDS Chain-Growth Polycondensation / Polycondensation / Living Polymerization / Controlled Polymerization / Architecture / Polyamides / Polyesters / Polyethers / Polythiophenes /
\end{abstract}

Polymerization can be classified into two categories: chain polymerization and step polymerization. Chain polymerization is initiated by the reaction of monomer and initiator, and then monomers react with the propagating group of polymers. If the chain polymerization proceeds in a living polymerization manner, the molecular weight of polymer is controlled by the feed ratio of monomer to initiator and the molecular weight distribution is narrow. In addition, the molecular weight increases in proportion to monomer conversion while retaining low polydispersity over the whole conversion range.

On the other hand, step polymerization is initiated by the reaction of monomers with each other, and propagation involves the reactions of all kinds of oligomers with themselves, as well as the reactions of those oligomers with monomers. Therefore, it is difficult to control the molecular weight of polymer, and polymer possesses a broad molecular weight distribution. Plotting the molecular weight values and the polydispersity against monomer conversion, the molecular weight does not increase much in the initial and middle stage and is accelerated in the last stage.
The polydispersity increases up to 2.0 in the last stage. Since conventional polycondensation proceeds in a step-polymerization manner, it has been thought to be essentially impossible to control molecular weight and polydispersity in polycondensation.

If, however, polycondensation proceeds in a chain polymerization manner, we call it "chain-growth polycondensation," condensation polymers having defined molecular weights and narrow molecular weight distributions would be obtained like living polymerization, because the polymer end groups in polycondensation are stable functional groups such as carboxyl group, amino group, and hydroxy group, and are generally always "living". Well-defined condensation polymers will not only have different physical properties from those of polymers with broad molecular weight distributions but also enable us to produce a variety of architectures containing condensation polymers by using the stable polymer end groups. Those architectures such as block copolymers and star polymers are expected to be arranged to form intriguing nanostructures by virtue of the strong intermolecular forces of condensation polymers.

${ }^{\dagger}$ To whom correspondence should be addressed (E-mail: yokozt01@kanagawa-u.ac.jp). 
Chain-growth polycondensation, however, is not a new concept. It occurs in the biosynthesis of many natural polymeric materials. Those polymers are perfect monodisperse macromolecules and are produced by the successive condensation of monomers with the polymer end groups that are activated by enzymes. For example, peptide elongation takes place in ribosome by the condensation of the amino group of an aminoacyl-tRNA with the terminal ester linkage of polypeptidyl-tRNA in the presence of peptidyl transferase. $^{1,2}$ In the synthesis of DNA, polycondensation proceeds by the reaction of a deoxyribonucleoside $5^{\prime}$-triphosphate with the $3^{\prime}-\mathrm{OH}$ terminus of polynucleoside by virtue of DNA polymerase. ${ }^{3}$ RNA is also synthesized by similar polycondensation mechanism. ${ }^{4,5} \mathrm{Cis}$-polyisoprene rubber is produced by the successive condensation of isopentenyl pyrophosphates with the terminal prenyl pyrophosphate moiety of polyisoprene in the presence of prenyltransferase. ${ }^{6-8}$ Although these syntheses proceed via many complicated and tightly controlled processes, the overall process could be regard as a kind of chaingrowth polycondensation.

The requirements for artificial chain-growth poly- condensation is to prevent the reaction of monomers with each other, which leads to conventional stepgrowth polycondensation, and to allow monomers to react selectively with an initiator and the propagating group. We have proposed two approaches to artificial chain-growth polycondensation of A-B type monomers (a nucleophilic and an electrophilic site in a monomer): (1) activation of polymer end group by substituent effects changed between monomer and polymer (Scheme 1) and (2) phase-transfer polymerization in biphase composed of monomer store phase and polymerization phase (Scheme 2). In the approach (1), the reaction between monomers is suppressed because the B of monomer (the ring in Scheme 1) is deactivated by the substituent effect of the A of monomer (the hook in Scheme 1). Accordingly, the monomer reacts with a reactive initiator, and the substituent effect of the A (the hook in Scheme 1) on the $\mathrm{B}$ (the ring in Scheme 1) is changed by bonding. If the polymer end group becomes more reactive than that of monomer by this changed substituent effect, the next monomer would react with the end group of unimer selectively to give dimer. The polymer end group of the dimer is also activated by the same substituent ef-
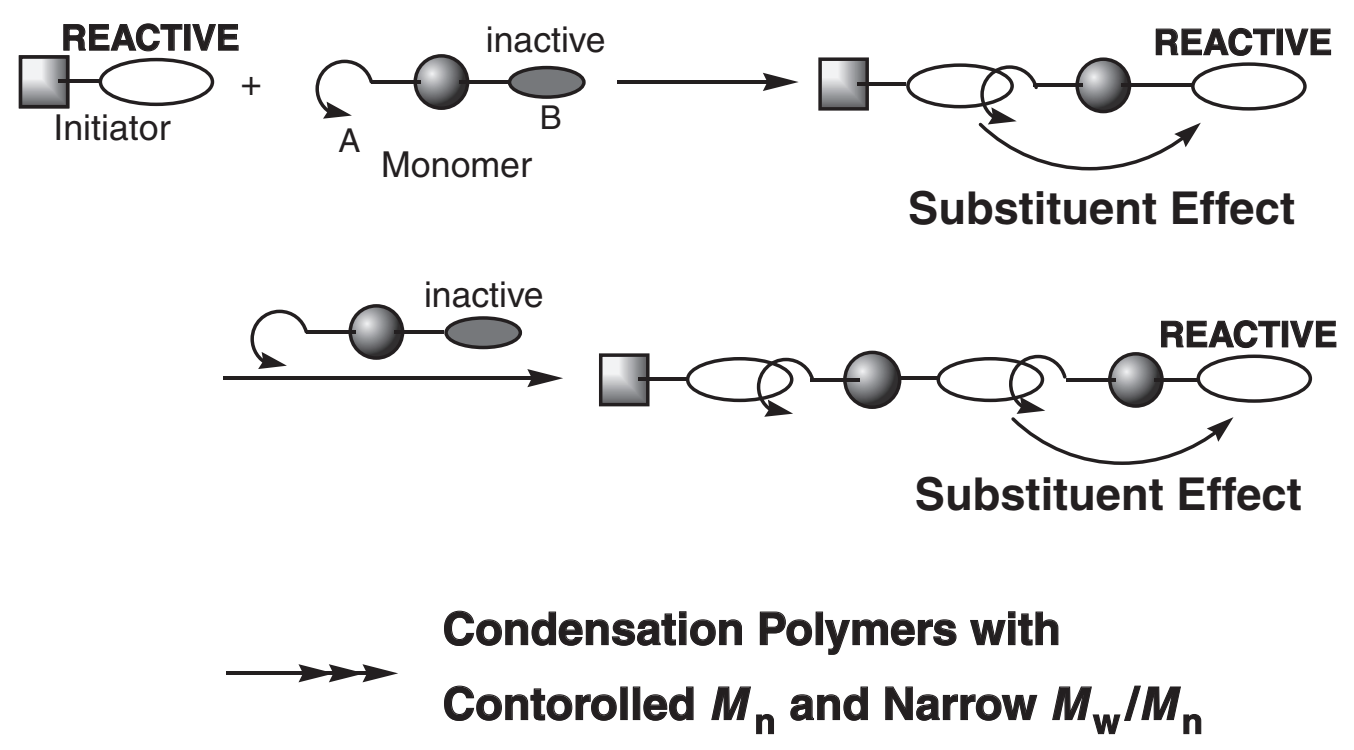

Scheme 1.

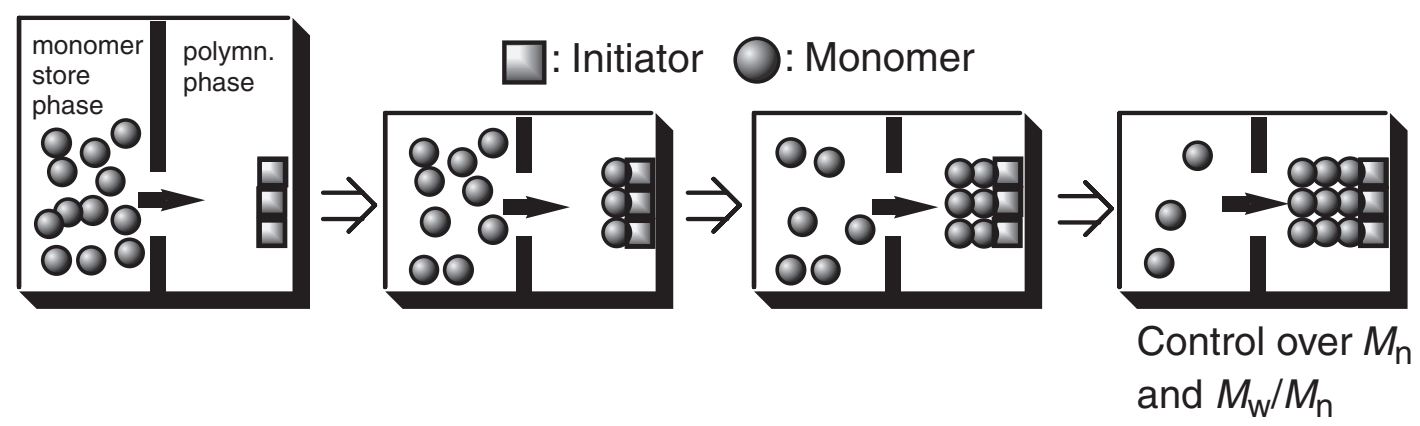

Scheme 2. 


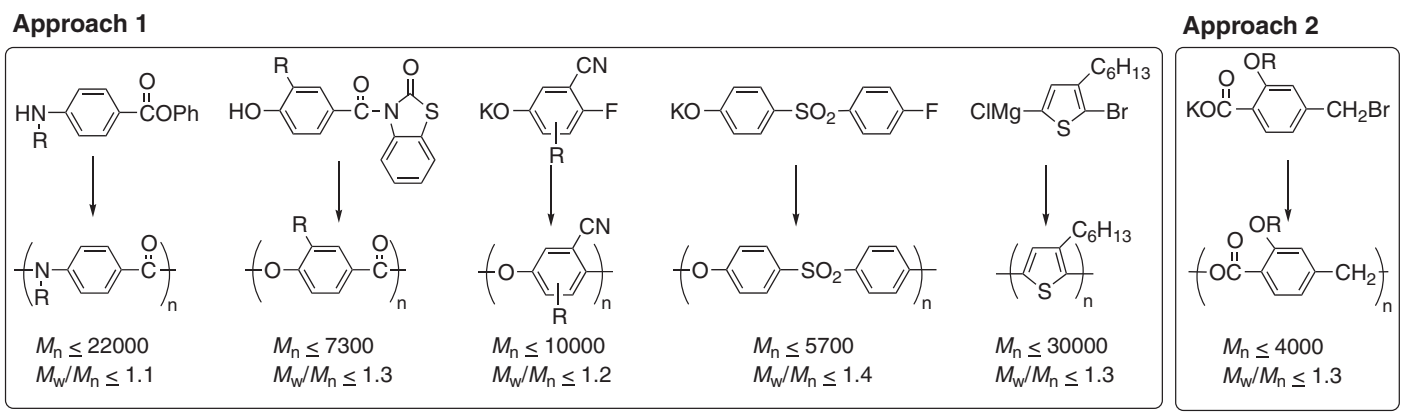

Scheme 3.

fect. Growth is expected to continue in a chain polymerization manner to yield well-defined condensation polymers. The observation that the polymer end group was more reactive than monomer has been reported in the polycondensation of alkali 4-halothiophenoxide, ${ }^{9}$ 4-fluoro-4'-hydroxydiphenylsulphone, ${ }^{10}$ 4-fluoro-4'hydroxybenzophenone, ${ }^{11}$ 4-halobenzenesulfinate, ${ }^{12}$ 2,6-dimethylphenol, ${ }^{13,14}$ and 4-bromo-2,6-dimethylphenol. ${ }^{15-17}$ However, condensation polymers with precisely controlled molecular weights and low polydispersities have not been obtained because of insolubility of polymers and of contamination of conventional step-growth polycondensation. The cationic polycondensation of phosphoranimines ${ }^{18-21}$ and the polycondensation of dimethylsulfoxonium methylide initiated by trialkylboranes ${ }^{22-27}$ yield well-defined polyphospahzenes and polymethylenes, respectively, but the structures of these propagating groups are different from the polymerizable groups of the monomers, and the monomers do not essentially react with each other.

The approach (2) is applicable for monomers, the substituent effect of which is not expected to be changed during polymerization. Monomers are stored in a phase like solid phase, in which monomers do not react physically with each other to prevent stepgrowth polymerization. An initiator is added in the other phase like liquid phase, and the monomer transferred to this phase would react with the initiator. If an adequate amount of the monomers are transferred, the monomers successively and selectively react with the polymer end group, resulting in polymers with low polydispersities. Some phase transfer polycondensations of bifunctional nucleophilic monomers and bifunctional electrophilic monomers yield polymers with relatively low polydispersities $\left(M_{\mathrm{w}} / M_{\mathrm{n}}=\right.$ $1.2-1.3)$ when the polymer end groups were more reactive than monomers. ${ }^{28-32}$ These polycondensations, however, are different from the concept of the approach (2), although the polymerizations took place in biphase. To the best of our knowledge, there has been no report about control over molecular weight and polydispersity of condensation polymers with this approach (2).

On the basis of the approach (1) and (2), we have been successful in achieving several chain-growth polycondensations. Monomers and the corresponding condensation polymers are shown in Scheme 3, as well as controllable range of $M_{\mathrm{n}}$ and $M_{\mathrm{w}} / M_{\mathrm{n}}$ values. In this review, we report these chain-growth polycondensations in Scheme 3 in this order and also polymer architectures including precisely controlled condensation polymers such as block copolymers and star polymers in some sections.

\section{POLYAMIDE}

\section{Polymerization}

The polycondensation of phenyl 4-(alkylamino)benzoate (1) proceeded homogeneously in the presence of phenyl 4-nitrobenzoate (2) as an initiator and base (a combination of $N$-triethylsilyl- $N$-octylaniline (4), CsF, and 18-crown-6) in THF at ambient temperature to yield well-defined aromatic polyamides, the molecular weight of which is controlled up to 22000 maintaining the polydispersity of 1.1 or below. ${ }^{33}$ Our proposed mechanism for this polycondensation is shown in Scheme 4. Base abstracts the proton of the amino group of monomer $\mathbf{1}$ to generate the aminyl anion $\mathbf{1}^{\prime}$. This anion site not only serves as a nucleophilic reactive site but also deactivates the phenyl ester moiety of $\mathbf{1}^{\prime}$ by this strong electron-donating ability to prevent the monomers from reacting each other. This anion $\mathbf{1}^{\prime}$ would react with initiator $\mathbf{2}$ having an electron-withdrawing group, because the phenyl ester moiety of $\mathbf{2}$ is more reactive than that of $\mathbf{1}^{\prime}$. The obtained amide $\mathbf{3}$ has a weak electron-donating amide linkage, and the phenyl ester moiety of 3 is more reactive than that of monomer. Thus, the monomer would react selectively with the phenyl ester moiety of $\mathbf{3}$. Growth would continue in a chain polymerization manner with the conversion of the strong electron-donating aminyl anion of monomer to the weak electron-donating amide group in polymer.

To elucidate whether chain-growth polymerization takes place in this polycondensation, the molecular 

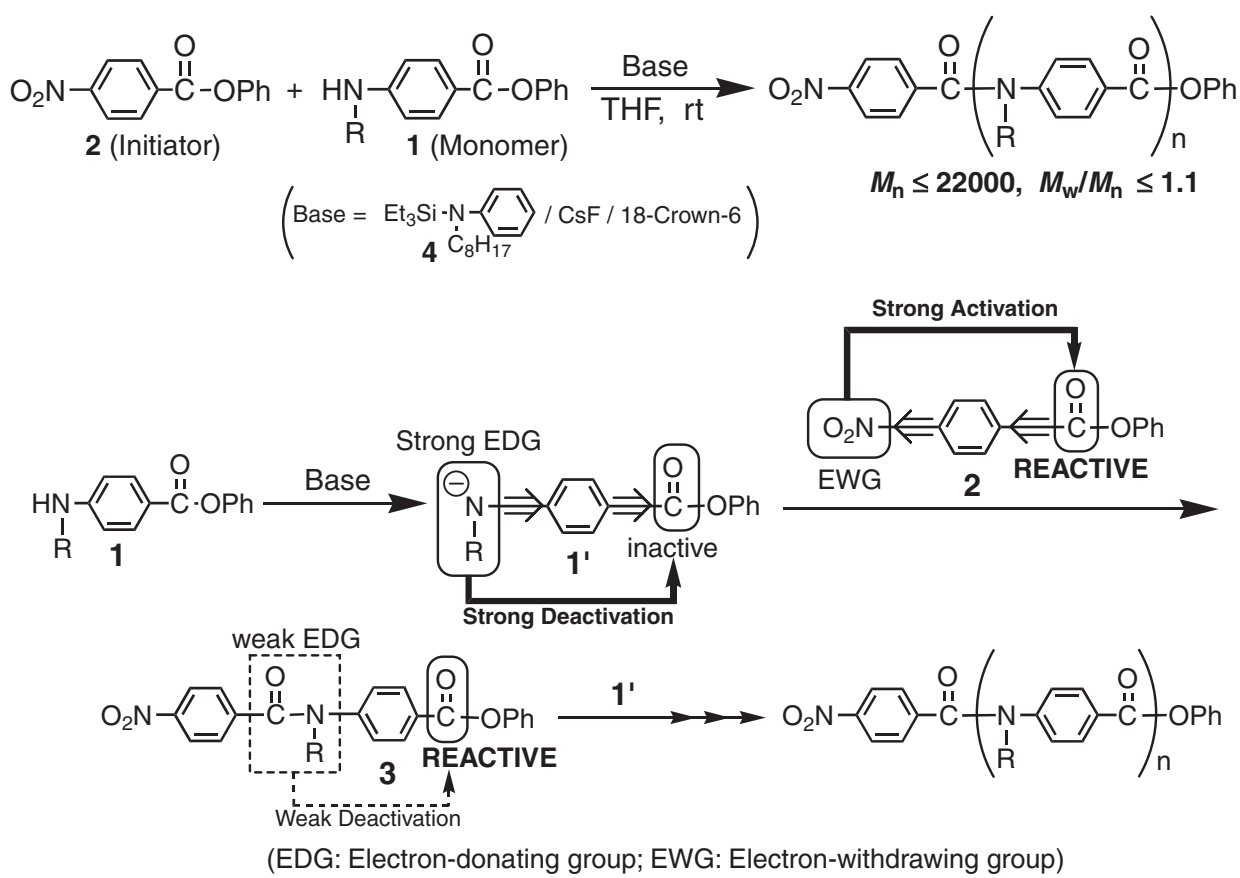

Scheme 4.
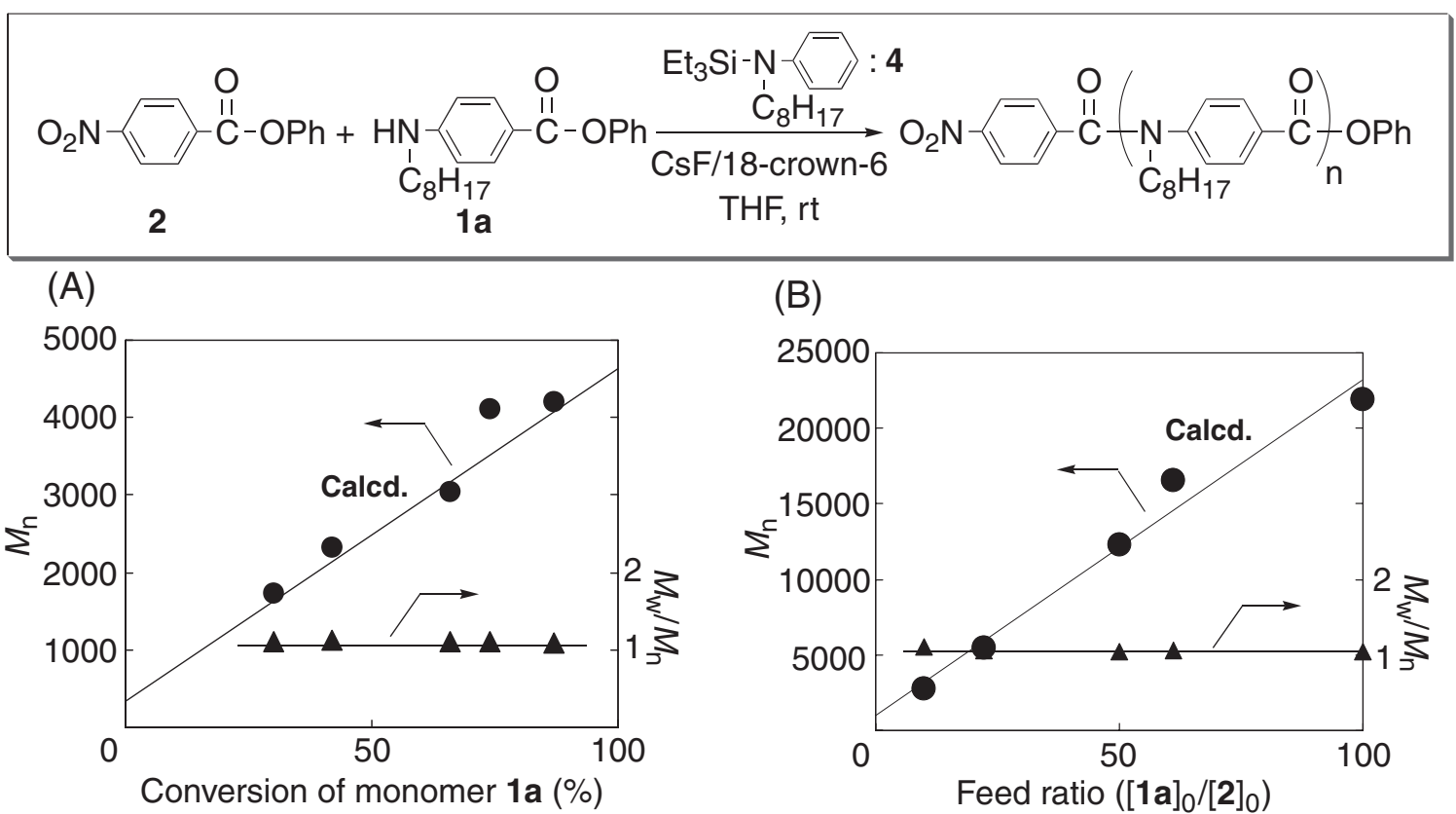

Figure 1. (A) $M_{\mathrm{n}}$ and $M_{\mathrm{w}} / M_{\mathrm{n}}$ values of poly1a, obtained with $4 / \mathrm{CsF} / 18$-crown-6 in the presence of 2 in THF at $25^{\circ} \mathrm{C}$, as a function of monomer conversion: $[\mathbf{1 a}]_{0}=0.33 \mathrm{M} ;[\mathbf{4}]_{0}=0.31 \mathrm{M} ;[\mathrm{CsF}]_{0}=0.33 \mathrm{M} ;[18 \text {-crown-6 }]_{0}=0.67 \mathrm{M} ;[2]_{0}=0.018 \mathrm{M}$. The line indicates the calculated $M_{\mathrm{n}}$ values assuming one polymer chain per unit 2. (B) $M_{\mathrm{n}}$ and $M_{\mathrm{w}} / M_{\mathrm{n}}$ values of poly1a, obtained with CsF/18-crown-6 in the presence of $\mathbf{2}$ in THF at $25^{\circ} \mathrm{C}$, as a function of the feed ratio of $\mathbf{1 a}$ to $\mathbf{2}$ : $[\mathbf{1 a}]_{0}=0.67 \mathrm{M} ;[\mathbf{4}]_{0}=0.73 \mathrm{M} ;[\mathrm{CsF}]_{0}=0.67 \mathrm{M} ;[18 \text {-crown-6 }]_{0}=$ $1.3 \mathrm{M} ;[2]_{0}=6.7-67 \mathrm{mM}$; conversion $=100 \%$. The line indicates the calculated $M_{\mathrm{n}}$ values assuming one polymer chain per unit 2.

weights and the molecular weight distributions were plotted against monomer conversion (Figure 1A). The $M_{\mathrm{n}}$ values of polymers increased in proportion to conversion, and the $M_{\mathrm{w}} / M_{\mathrm{n}}$ ratios were less than 1.12 over the whole conversion range. As mentioned in the Introduction, this polymerization behavior indicates chain-growth polymerization. In another series of experiments, the polymerization was carried out with varying feed ratio of monomer to initiator $\left([\mathbf{1 a}]_{0} /[\mathbf{2}]_{0}\right)$. As shown in Figure $1 \mathrm{~B}$, the $M_{\mathrm{n}}$ values were in good agreement with the calculated values assuming that one polymer chain forms per unit $\mathbf{2}$ until $M_{\mathrm{n}}=22000$. The molecular weight distributions were quite narrow, maintaining the $M_{\mathrm{w}} / M_{\mathrm{n}}$ ratio below 1.1 over the whole $[\mathbf{1 a}]_{0} /[\mathbf{2}]_{0}$ range. This result implies that the polycondensation proceeded from initiator $\mathbf{2}$ 


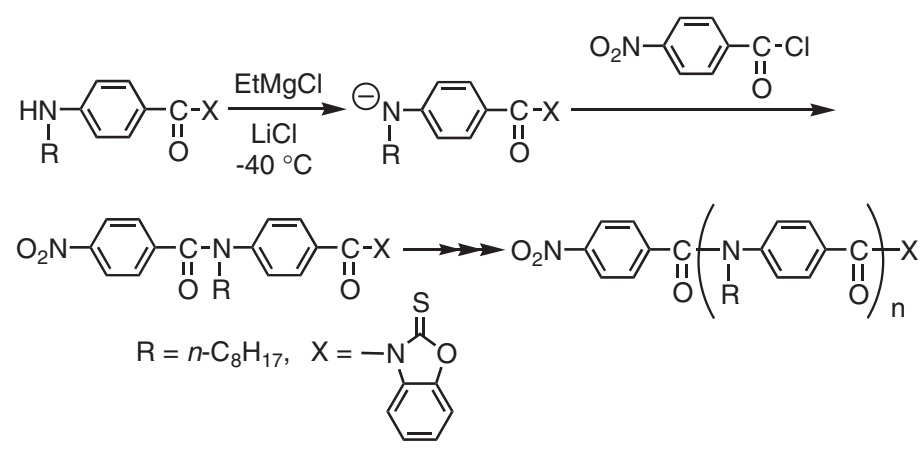

Scheme 5.

in a chain-growth polymerization manner like living polymerizations of vinyl monomers and cyclic monomers.

The same well-defined polyamide has been also synthesized by Ueda and his colleague (Scheme 5). ${ }^{34}$ The leaving group of the monomer and base are different from ours. This active amide of the monomer is more reactive than the phenyl ester of 1a. However, the reaction of monomers with each other, leading to conventional step-growth polycondensation, was prevented, implying that the aminyl anion generated by Grignard reagent effectively deactivates the active amide moiety, in a similar manner of the polymerization of 1a.

Monomer 1a also undergoes chain-growth polycondensation even without initiators to yield polyamides with low polydispersities. ${ }^{35}$ One might think that the conventional step-growth polycondensation would occur in the absence of the initiator, because oligomers formed during reaction have the reactive amino group and phenyl ester moiety in both ends, and therefore those oligomers would react with each other. However, the polymerization showed the behavior of living chain-growth polymerization; the $M_{\mathrm{n}}$ values increased in proportion to conversion and the $M_{\mathrm{w}} / M_{\mathrm{n}}$ ratios were less than 1.2 over the whole conversion range (Figure 2). Furthermore, as the amount of $\mathbf{4}$ was increased, the polymerization proceeded faster to yield polyamides with higher $M_{\mathrm{n}}$ values and lower polydispersities (Table I). Especially, the polyamide with $M_{\mathrm{n}}$ of 21300 and $M_{\mathrm{w}} / M_{\mathrm{n}}$ of 1.07 was obtained by the polycondensation of 1a with 1.5 equiv of 4 only for $10 \mathrm{~min}$. This polymerization probably involves the formation of the dimer of $\mathbf{1 a}$, which initiates chain-growth polymerization faster than stepgrowth polymerization. This self-initiated living-like polymerization is a unique type of polymerization that would take place only by monomers that can react with each other.

\section{Diblock Copolymers}

Taking advantage of living polymerization nature in this polycondensation, block copolymers of aromat-

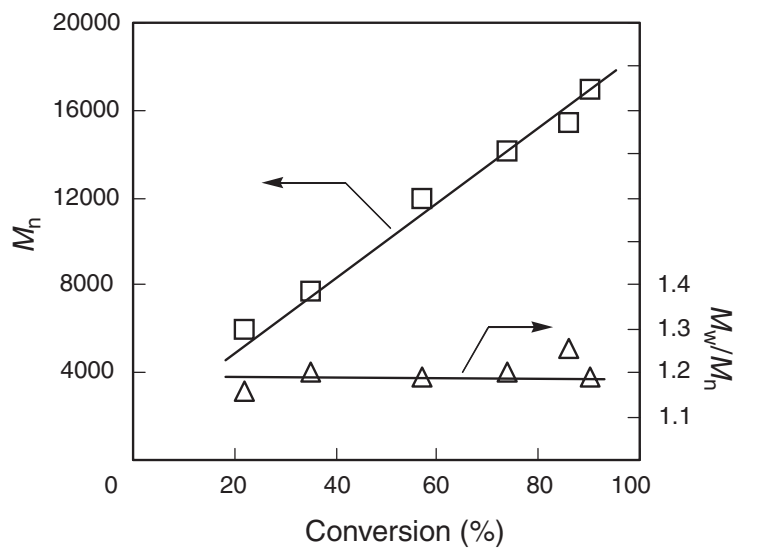

Figure 2. $M_{\mathrm{n}}$ and $M_{\mathrm{w}} / M_{\mathrm{n}}$ values of poly1a, obtained with 4/ $\mathrm{CsF} / 18$-crown- 6 in THF at $25^{\circ} \mathrm{C}$, as a function of monomer conversion: $[\mathbf{1 a}]_{0}=[\mathbf{4}]_{0}=[\mathrm{CsF}]_{0}=0.67 \mathrm{M} ;[18 \text {-crown-6 }]_{0}=$ $1.33 \mathrm{M}$.

Table I. Polycondensation of $1 \mathrm{a}$ with $\mathbf{4}^{\text {a }}$

\begin{tabular}{ccccc}
\hline$[\mathbf{4}]_{0} /[\mathbf{1 a}]_{0}$ & Time & Conversion $(\%)^{\mathrm{b}}$ & $M_{\mathrm{n}}{ }^{\mathrm{c}}$ & $M_{\mathrm{w}} / M_{\mathrm{n}}{ }^{\mathrm{c}}$ \\
\hline 0.9 & $24 \mathrm{~h}$ & 89 & 15400 & 1.34 \\
1.0 & $23 \mathrm{~h}$ & 90 & 17000 & 1.19 \\
1.2 & $4.3 \mathrm{~h}$ & 88 & 18900 & 1.10 \\
1.5 & $10 \mathrm{~min}$ & 91 & 21300 & 1.07 \\
& $30 \mathrm{~min}$ & 93 & 24400 & 1.15 \\
\hline
\end{tabular}

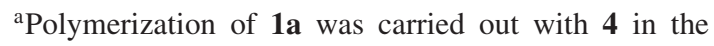
presence of CsF/18-crown-6 in THF $\left([\mathbf{1 a}]_{0}=0.67 \mathrm{M}\right.$; 1.0 equiv of $\mathrm{CsF}$ and 2.0 equiv of 18 -crown-6 to 4) at $25^{\circ} \mathrm{C}$. ${ }^{\mathrm{b}}$ Determined by HPLC. ${ }^{\mathrm{c}}$ Determined by GPC based on polystyrene standards (eluent: THF).

ic polyamides can be synthesized in one pot. Scheme 6 shows an example of the block copolymer of $N$-alkyl and $\mathrm{N}$-H polyamides. ${ }^{36}$ Since the monomer having the primary amino group did not polymerize under this polymerization condition, monomer $\mathbf{1 b}$ having the 4octyloxybenzyl moiety as a protecting group on nitrogen was used. First, $N$-octyl monomer 1a was polymerized, and then monomer $\mathbf{1 b}$ and base were added into the reaction mixture to yield the block copolymer of poly1a and poly1b. The GPC profiles of poly1a and the block copolymer are shown Figure 3A. The elution curve of the block copolymer clearly shifted toward the higher molecular weight region, while retain- 


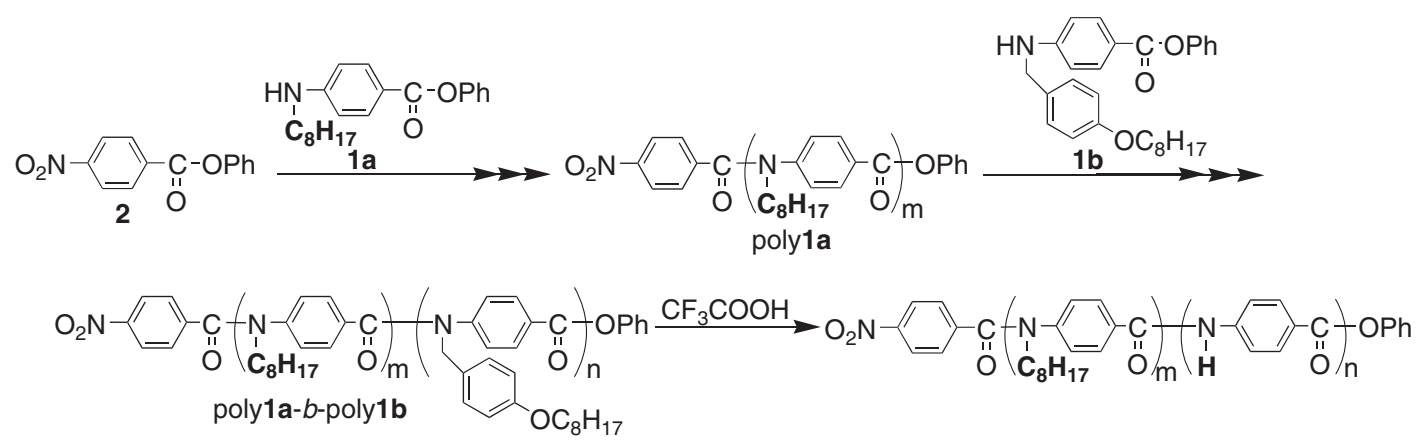

Scheme 6.

(A)

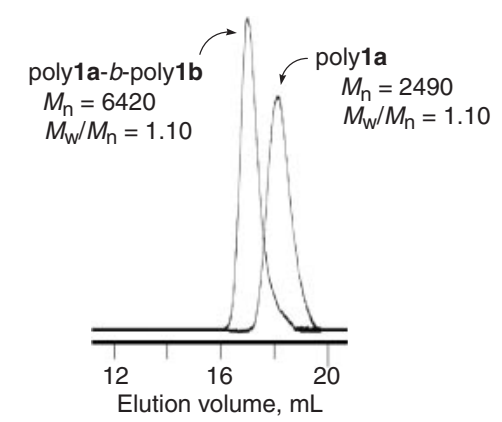

(B)

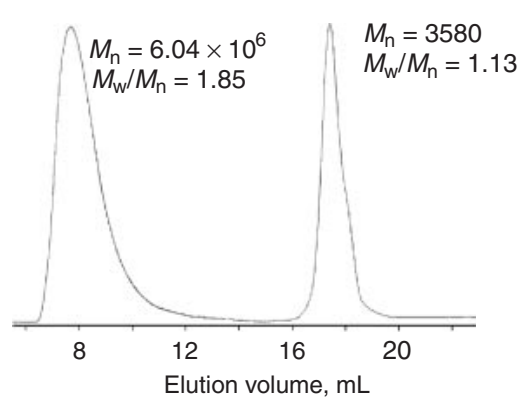

Figure 3. GPC profiles of polymer (eluent: THF). (A) Synthesis of the block copolymer of $\mathbf{1 a}$ and $\mathbf{1 b}$ by monomer addition method: poly1a as a prepolymer $\left([\mathbf{1} \mathbf{a}]_{0} /[\mathbf{2}]_{0}=9.6\right), M_{\mathrm{n}}=2490, M_{\mathrm{w}} / M_{\mathrm{n}}=1.10$; poly1a- $b$-poly $\mathbf{1 b}$ as a postpolymer $\left([\operatorname{added} \mathbf{1 b}]_{0} /[\mathbf{2}]_{0}=10.2\right)$, $M_{\mathrm{n}}=6420, M_{\mathrm{w}} / M_{\mathrm{n}}=1.10$. (B) The block copolymer of poly( $N$-octyl- $p$-benzamide) and poly ( $p$-benzamide) obtained by the deprotection of the 4-octyloxybenzyl groups on poly1a- $b$-poly1b with TFA.
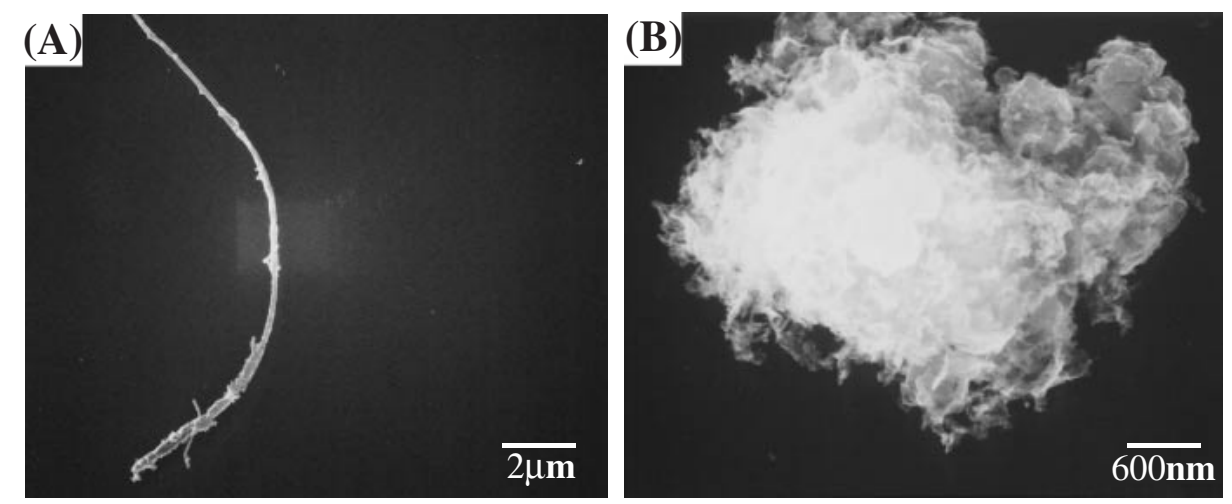

Figure 4. SEM images (A, B) of the supramolecular assemblies of the block copolymer of poly( $N$-octyl- $p$-benzamide $)$ and poly $(p$ benzamide) from the copolymer solution in THF dried at $25^{\circ} \mathrm{C}$ on a silicon wafer and sputter coated with carbon.

ing the narrow molecular weight distribution.

The 4-octyloxybenzyl protecting group could be removed with trifluoroacetic acid (TFA) quantitatively to afford the desired block copolymer. The GPC profile of this block copolymer showed not only the peak corresponding to the block copolymer but also the peak in the higher molecular weight region (Figure 3B). We anticipated that this peak was attributed to self-assembly of the block copolymer by virtue of the intermolecular hydrogen bonding of amide linkage. Scanning electron microscopy (SEM) was used to visualize the supramolecular self-assemblies of the block copolymer. Surprisingly, the SEM images revealed that $\mu \mathrm{m}$-sized bundles were formed as well as aggregates of flake structures (Figure 4). The length of the bundle was in the range of $4-15 \mu \mathrm{m}$ and their diameter was in the range of $150-250 \mathrm{~nm}$.

The block copolymers of the aromatic polyamides and conventional polymers also can be prepared by the reaction of the polymer end group of the polyamide with the living propagating group of conventional polymers. Thus, the phenyl ester moiety of the polyamide reacts with the anionic living end of polymers, whereas the amino group of the polyamide does 


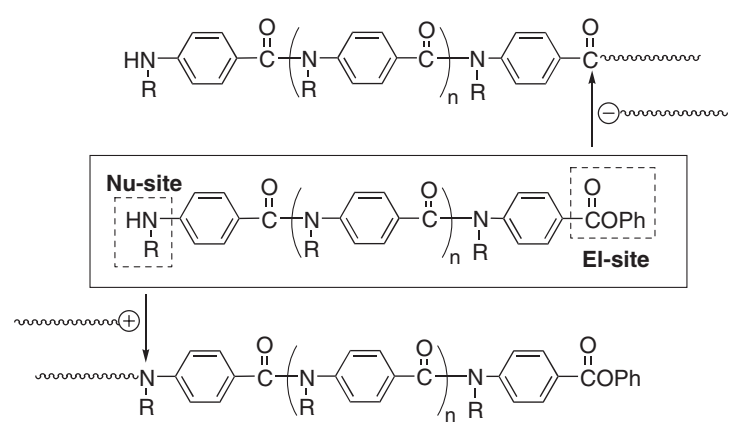

Scheme 7.

with the cationic living end of polymers (Scheme 7).

For example, poly(ethylene glycol) (PEG) monomethyl ether was reacted with polyamide in the presence of $\mathrm{NaH}$ to yield the block copolymer of polyamide and PEG (Scheme 8). ${ }^{37}$ Excess of PEG was used in this polymer reaction, but unreacted PEG could be washed out with water to isolate the block copolymer.

The polyamide having the terminal amino group in Scheme 7 was prepared by the polymerization of 1a with initiator 5 bearing the $t$-butoxycarbonyl (Boc) group on the amino group, followed by removal of the Boc group with TFA; the same polyamide was also obtained by the above-mentioned polymerization without initiators, but the molecular weight is not predictable. The terminal amino group of this polyamide
6 reacted with living poly(THF) to yield the block copolymer of polyamide and poly(THF) (Scheme 9). ${ }^{38}$

Another approach to the block copolymers of the aromatic polyamides and conventional polymers is the chain-growth polycondensation from macroinitiators derived from conventional polymers, because this polycondensation for polyamide can be initiated from the simple phenyl ester moiety on many kinds of molecules including polymers. The diblock copolymer of polystyrene and the polyamide was synthesized with this approach (Scheme 10). ${ }^{39}$ The polymerization of styrene was initiated with sec-butyl lithium, followed by quenching by dry ice to yield polystyrene with the carboxyl group as an end group. The carboxyl group was converted into the phenyl ester moiety by using a condensation agent and phenol. This polystyrene was used as a macroinitiator for the chain-growth polycondensation for polyamide. When the molecular weights of the macroinitiators were low, the desired block copolymers with low polydispersities were obtained in good yields. Using the macroinitiators with higher molecular weights, however, it became difficult to obtain the block copolymers quantitatively. Probably polymer effect of polystyrene decreases the efficiency of initiation of chain-growth polycondensation.

\section{Triblock Copolymers}

When a difunctional phenyl ester such as simple

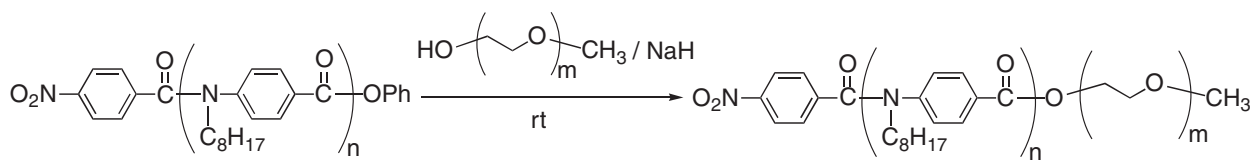

Scheme 8.

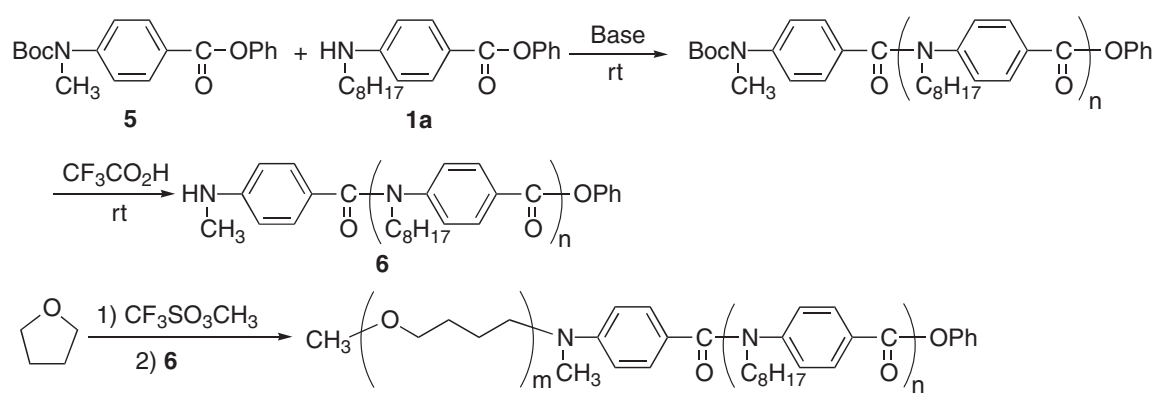

Scheme 9.
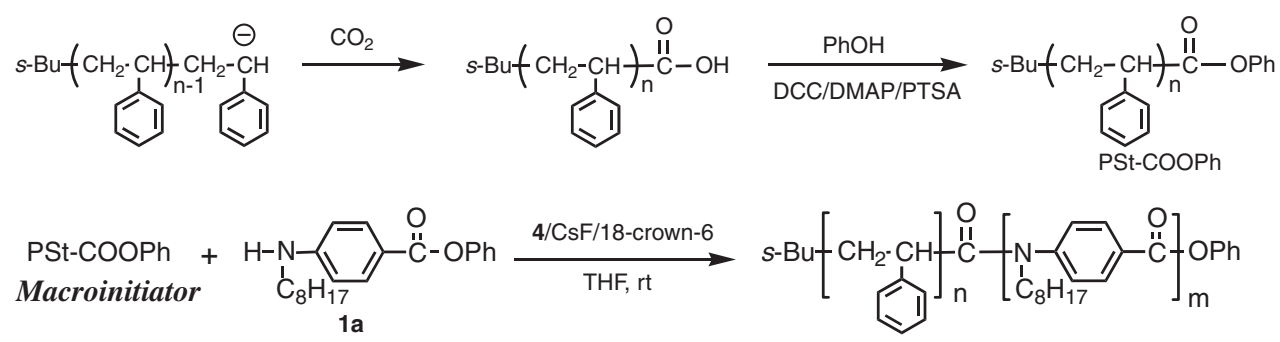

Scheme 10. 


$$
\begin{aligned}
& \text { PhO-C }
\end{aligned}
$$

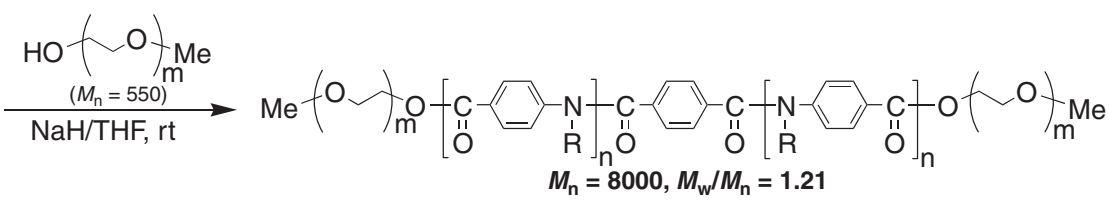

\section{Scheme 11.}

phenyl terephthalate is used as an initiator, the polyamide with the phenyl ester moieties in both ends is obtained, which can be utilized for the synthesis of BAB-type triblock copolymers. For example, the nucleophilic substitution with PEG alkoxide took place on these phenyl ester acyl groups to yield well-defined PEG-polyamide-PEG triblock copolymer (Scheme 11). ${ }^{40}$

In the synthesis of the diblock copolymer of polyamide and poly(THF) mentioned above, the polymerization of THF was carried out with trifluoromethanesulfonic anhydride instead of methyl trifluoromethanesulfonate, followed by quenching with polyamide 6 to afford polyamide-poly(THF)-polyamide triblock copolymer (Scheme 12). ${ }^{38}$

Furthermore, poly1a- $b$-poly1b, mentioned in the above section of Diblock Copolymers, was reacted with PEG alkoxide, followed by deprotection to yield the triblock copolymer of $N$-alkyl and $N-\mathrm{H}$ polyamides and PEG (Scheme 13). ${ }^{41}$ Since this block copolymer consists of a hydrophobic rod unit, a hydrogen bonding rod unit, and a hydrophilic coil unit, a variety of self-assemblies are expected depending on solvents that dissolve this block copolymer. In addi- tion, it would be also interesting to observe the variation of supramolecular assemblies by changing the sequence of the three units in this triblock copolymer.

\section{Star Polymers}

When initiator 7 bearing the three phenyl ester moieties is used for chain-growth polycondensation, star polyamides can be obtained. Scheme 14 shows examples of star block copolymers 8 having the well-defined arms of the diblock copolymers described above. ${ }^{42,43}$ An intriguing feature of star block copolymers is variation of physical properties by exchanging core unit and shell unit, even though the arm is derived from the same diblock copolymer. Thus, star polymer 8b with $\mathrm{N}-\mathrm{H}$ polyamide as a shell unit was arranged in a supramolecular self-assembly in THF, which was observed in GPC chromatogram, whereas star polymer 8c with $\mathrm{N}-\mathrm{H}$ polyamide as a core unit was not (Figure 5). ${ }^{42}$

\section{POLYESTER}

The synthesis of well-defined polyester had been difficult than that of polyamide, because polyester

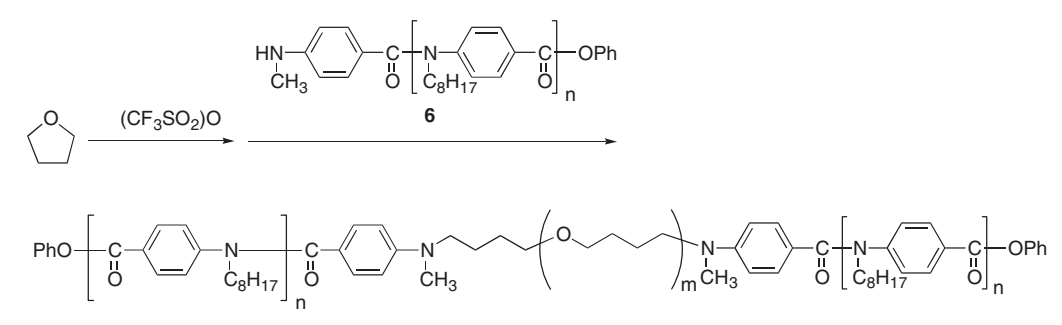

Scheme 12.

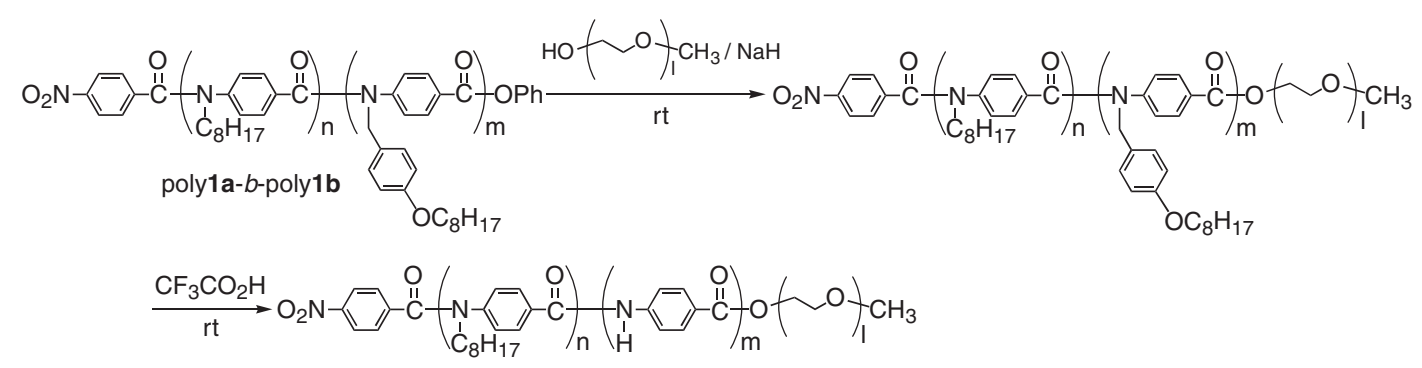

Scheme 13. 


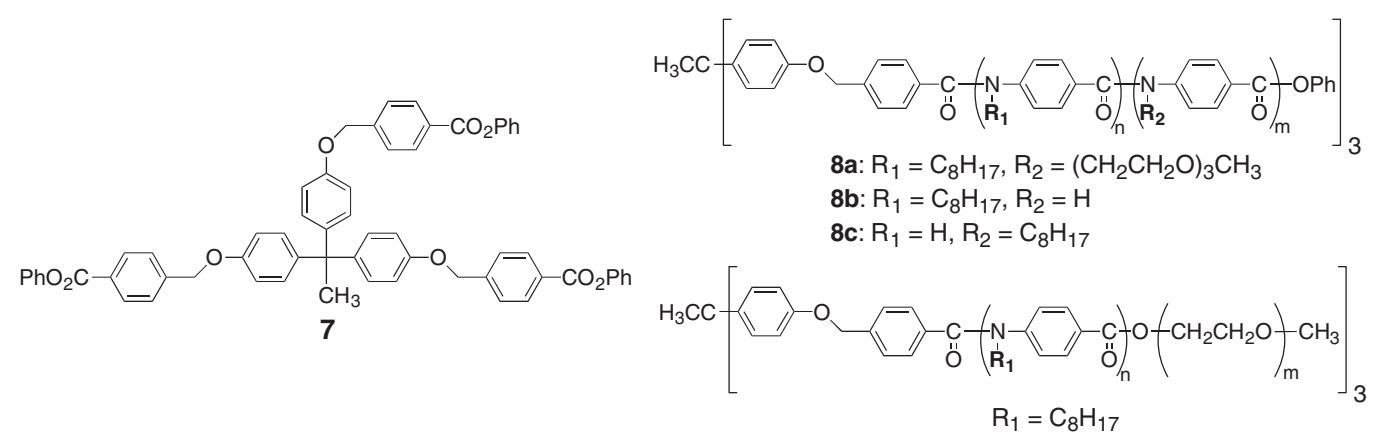

Scheme 14.

(A)

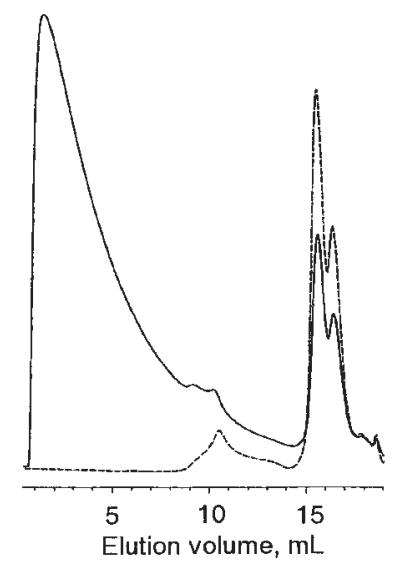

(B)

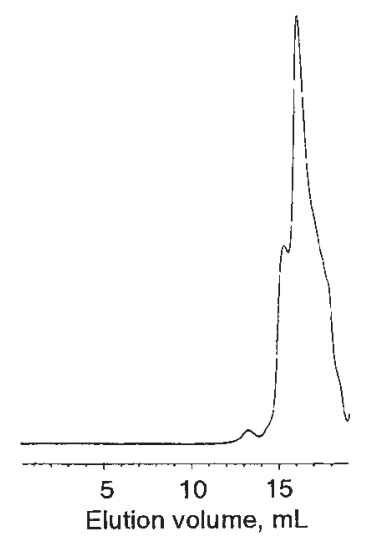

Figure 5. GPC profiles of star polymers (eluent: THF). (A) $\mathbf{8 b}$ : just after making a sample solution (dush line); $2 \mathrm{~h}$ after making a sample solution (solid line). (B) $8 \mathbf{c}$.

easily undergoes transesterification. ${ }^{44}$ Even though chain-growth polycondensation proceeds from an initiator until middle stage, if the residual monomers attack the polymer ester linkage to generate the cleaved chain with the phenoxide moiety and the acyl group at both ends, conventional step-growth polycondensation starts. To prevent transesterification, we chose monomer 9 having an active amide moiety which shows a good leaving nature to polymerize under mild conditions (Scheme 15). The leaving group of $\mathbf{9}$, benzothiazolone, ${ }^{45}$ was selected among other leaving groups on the basis of the results of model reactions. ${ }^{46,47}$ In the polymerization of 9 with tertiary amine in the presence of initiator $\mathbf{1 0}$ at room temperature, the molecular weight was controlled up to 2700 . When the polyesters with higher molecular weights than that were attempted to be prepared, transesterification occurred. ${ }^{47}$ However, when the polymerization was carried out at $-30^{\circ} \mathrm{C}$ with $\mathrm{Et}_{3} \mathrm{SiH}, \mathrm{CsF}$, and 18 -crown-6 as a stronger base system, transesterification was almost depressed. ${ }^{48}$ The maximum controlled molecular weight was still 3500 , but it is not due to transesterification but due to low solubility of this polyester. We now can control the molecular weight until 7000 by the polymerization of the monomer with a different side chain. ${ }^{49}$

The proposed mechanism is shown in Scheme 15. The basic idea is the same as the polymerization for polyamide. Phenoxide generated with base deactivates the acyl group by means of its strong electron-donating character and suppresses the reaction between monomers. On the other hand, this phenoxide would react with an active initiator having a weak electrondonating group to give an ester. Since the ester linkage is a weaker electron-donating group than phenoxide, the acyl group of this ester is more reactive than that of monomer, and the next monomer would react with the terminal acyl group of the ester. Growth would continue in a chain-polymerization manner.

The polymerization behavior also showed living polymerization nature as in the case of polyamide (Figure 6). Thus, the molecular weights increased in proportion to conversion maintaining low polydispersities, and also increased in proportion to the feed ratio of monomer to initiator. Furthermore, we checked both polymer ends during polymerization and of polymers obtained at a variety of the feed ratios. The polymers from chain-growth polymerization have both ends $\mathbf{a}$ and $\mathbf{b}$, the ratio of which is 1 to 1 , whereas the polymers from conventional step-growth polymerization have only end group $\mathbf{b}$; the other end group is not a but the hydroxy group. Therefore, when only chain polymerization takes place from 10, the ratio of $\mathbf{a}$ to $\mathbf{b}$ is 1.0, and when both chain-growth and step-growth polymerizations occur, the ratio of a to b is smaller than 1.0. As shown in Figure 6, these ratios always keep 1.0 in these experiments. Consequently, these results show that the polycondensation for polyester also proceeds in a chain polymerization manner.

\section{POLYETHER}

\section{Polymerization}

Monomer 11a for polyether did not polymerize at $150^{\circ} \mathrm{C}$ by itself, but polymerized in the presence of active aromatic fluorine 12, implying that $\mathbf{1 2}$ initiated 

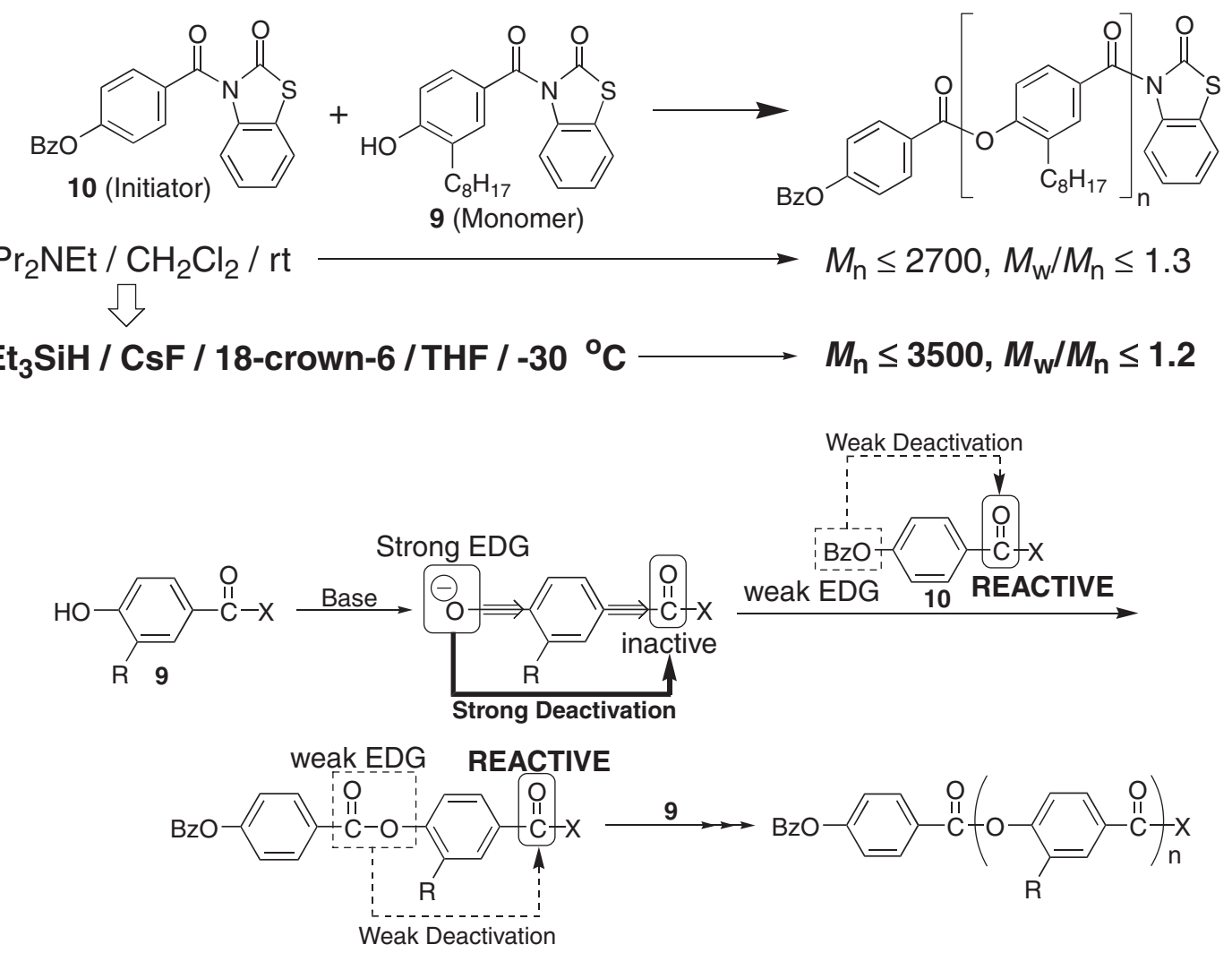

Scheme 15.

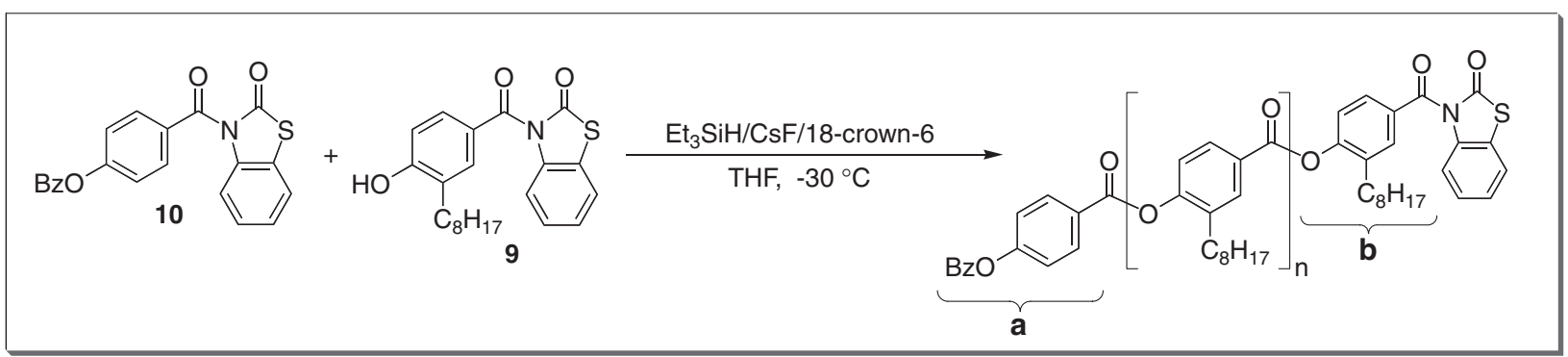

(A)
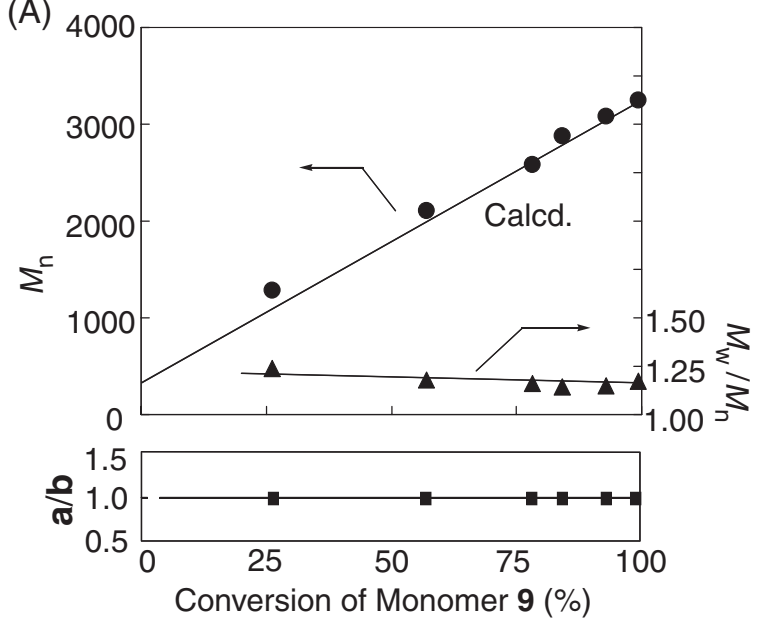

(B)

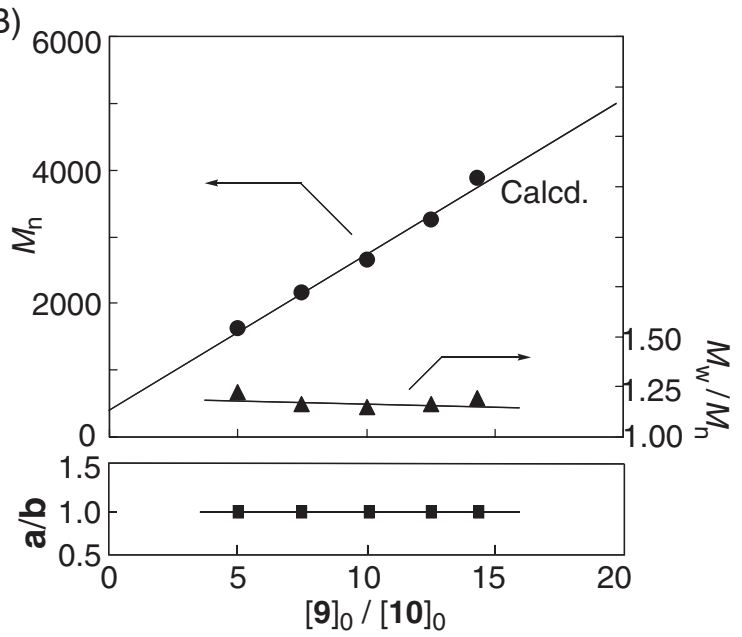

Figure 6. (A) $M_{\mathrm{n}}$ and $M_{\mathrm{w}} / M_{\mathrm{n}}$ values and the ratio of initiator unit to end group (a/b) of poly9, obtained with $\mathrm{Et} 3 \mathrm{SiH} / \mathrm{CsF} / 18$-crown-6 in the presence of $\mathbf{1 0}$ in THF at $-30^{\circ} \mathrm{C}$, as a function of monomer conversion: $[9]_{0}=0.17 \mathrm{M} ;\left[\mathrm{Et}{ }_{3} \mathrm{SiH}\right]_{0}=[\mathrm{CsF}]_{0}=0.17 \mathrm{M}$; $[18 \text {-crown-6 }]_{0}$ $=0.33 \mathrm{M} ;[\mathbf{1 0}]_{0}=0.013 \mathrm{M}$. The line indicates the calculated $M_{\mathrm{n}}$ values assuming one polymer chain per unit 10. (B) $M_{\mathrm{n}}$ and $M_{\mathrm{w}} / M_{\mathrm{n}}$ values of poly9, obtained with $\mathrm{Et}_{3} \mathrm{SiH} / \mathrm{CsF} / 18$-crown-6 in the presence of $\mathbf{1 0}$ in $\mathrm{THF}$ at $-30^{\circ} \mathrm{C}$, as a function of the feed ratio of $\mathbf{9}$ to 10: $[\mathbf{9}]_{0}=$ $0.17 \mathrm{M} ;\left[\mathrm{Et}_{3} \mathrm{SiH}\right]_{0}=[\mathrm{CsF}]_{0}=0.17 \mathrm{M} ;[18 \text {-crown-6 }]_{0}=0.33 \mathrm{M} ;[\mathbf{1 0}]_{0}=8.3-24 \mathrm{mM}$; conversion $=100 \%$. The line indicates the calculated $M_{\mathrm{n}}$ values assuming one polymer chain per unit $\mathbf{1 0}$. 

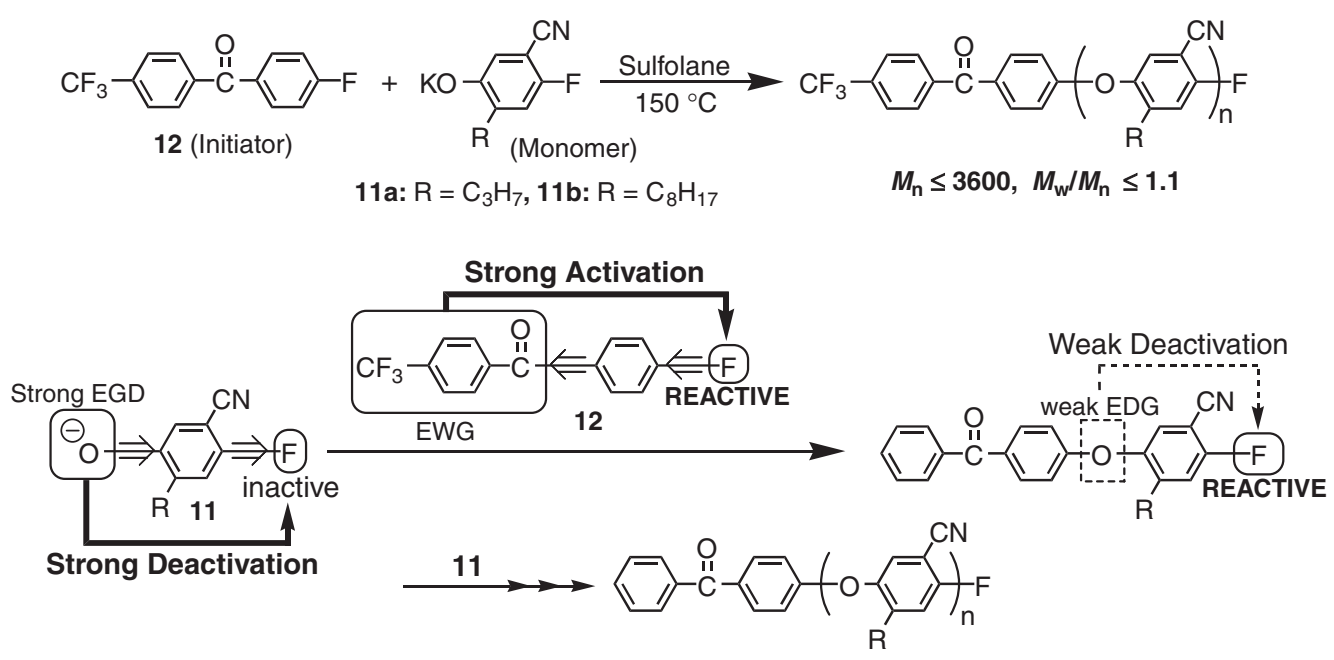

Scheme 16.

the polymerization of 11a, that is chain-growth polycondensation. Actually, polyethers with low polydispersities were obtained in this polycondensation (Scheme 16). ${ }^{50}$

We had thought at first that the chain-growth polycondensation for polyethers was difficult to be attained, because difference of substituent effects between monomer and polymer is small; the hydroxy group of monomer and the ether linkage of polymer are similar electron-donating groups. The point for this successful chain-growth polycondensation is thought to be the use of phenoxide in monomer instead of phenol. The phenoxide is a much stronger electron-donating group than the ether linkage, and the fluorine of monomer is strongly deactivated by the negative charge of phenoxide to prevent monomers from reacting each other. Thus, monomer 11 reacts with active initiator $\mathbf{1 2}$ to give an ether. The fluorine of this ether gets more reactive than that of monomer, because the ether linkage is less electrondonating than the phenoxide of the monomer. Consequently, growth would continue in a chain polymerization manner.

Similar experiments were conducted to confirm chain polymerization. As shown in Figure 7, the molecular weights increased in proportion to conversion, while retaining narrow molecular weight distributions, and the ratios of both terminal groups is always 1.0. This ratio was easily estimated by ${ }^{19}$ F NMR spectra, because the initiator bears the trifluoromethyl group, and the polymer end group is fluorine. The molecular weights also increased in proportion to the feed ratio of monomer 11a to initiator 12, and was in good agreement with the calculated values, although the polymers having higher molecular weights than 4000 were not soluble in the reaction solvent. ${ }^{51}$ These results indicate that the polycondensation for polyether also proceeded from initiator $\mathbf{1 2}$ in a chain-growth polymerization manner like living polymerization.

As mentioned in the above mechanism, low reactivity of the fluorine of monomer 11a is responsible for this chain-growth polycondensation. We could estimate the reactivities of the fluorines of initiator 12, polymer end group, and monomer 11a by the chemical shifts of ${ }^{19} \mathrm{~F}$ NMR spectra, because it has been reported that the signal of more reactive aromatic fluorine appears in the lower field. ${ }^{52}$ On the basis of this report, the initiator fluorine is the most reactive, and the next is the polymer end fluorine. The monomer fluorine is far less reactive (Figure 8). The order of these reactivities is consistent with the requirements for this chain-growth polycondensation.

\section{Solvent Effect on Polymerization}

Since the above polymerization solvent, sulfolane, is not a general solvent, the polymerization was carried out in various solvents by using more soluble monomer $\mathbf{1 1 b} .^{53}$ In $N, N$-dimethylimidazolidinone (DMI), tetraglyme, and sulfolane, the polymerization proceeded homogeneously at $150^{\circ} \mathrm{C}$. In the former two solvents, however, polyethers with broad molecular weight distributions were obtained, whereas in sulfolane polyethers with low polydispersities were yielded and the molecular weights were controlled by the feed ratio of monomer $\mathbf{1 1 b}$ to initiator $\mathbf{1 2}$.

The polyethers obtained in DMI and sulfolane were also analyzed by MALDI-TOF mass spectra, respectively (Figure 9). The spectrum of the polymer obtained in DMI contains two major distributions: polymers without the initiator unit from step-growth polycondensation $(\mathrm{Sp})$ and polymers with the initiator unit from chain-growth polycondensation $(\mathrm{Cg})$. On the other hand, the spectrum of the polymer obtained in sulfolane shows only one series of peaks $(\mathrm{Cg})$ derived from chain-growth polycondensation. Consequently, the chain-growth polycondensation of 11b 


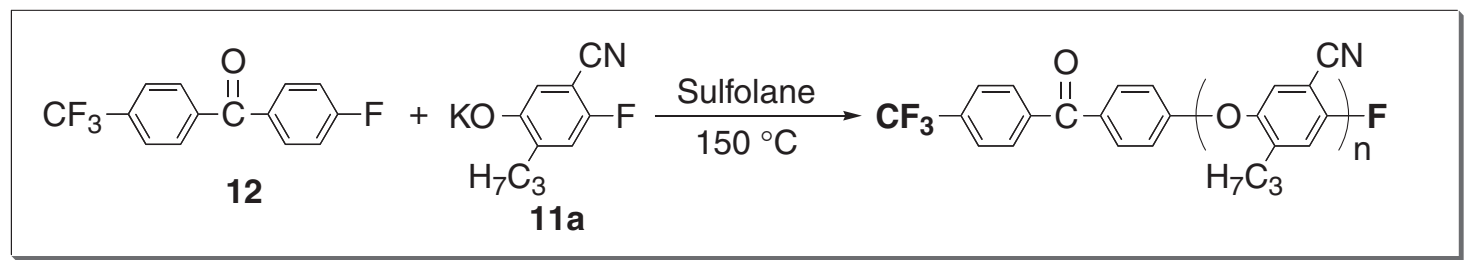

(A)

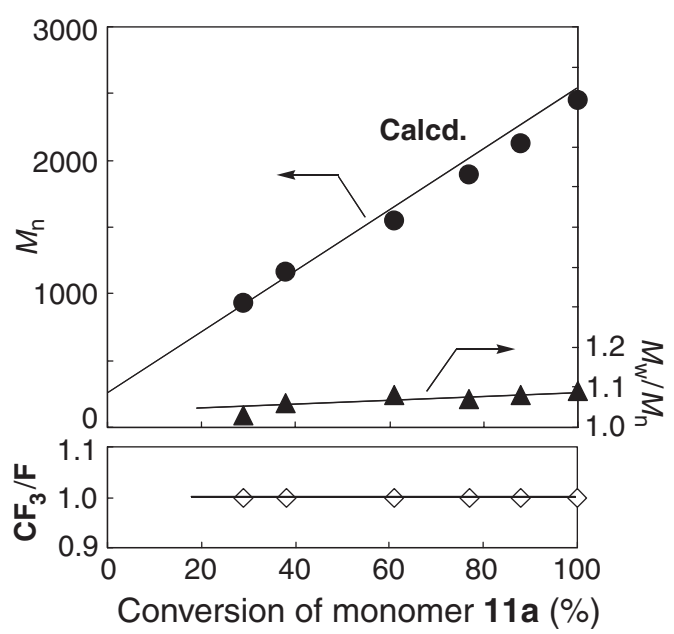

(B)

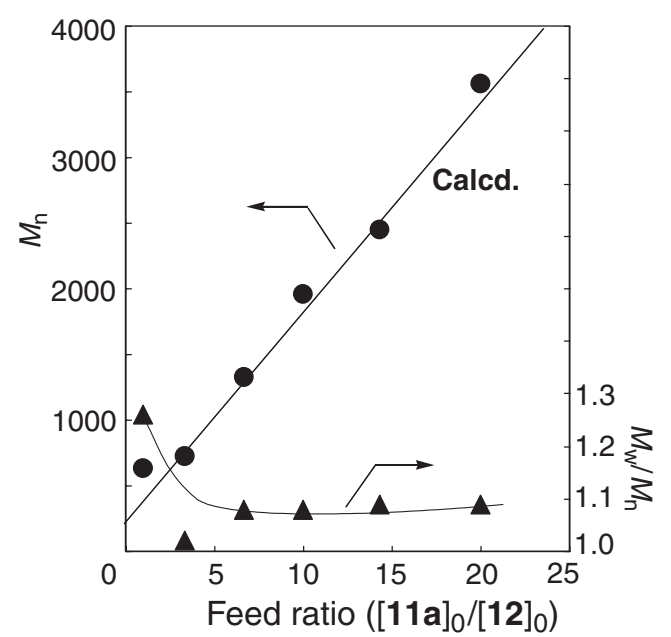

Figure 7. (A) $M_{\mathrm{n}}$ and $M_{\mathrm{w}} / M_{\mathrm{n}}$ values of poly11a and the ratios of initiator unit to end group $\left(\mathrm{CF}_{3} / \mathrm{F}\right)$ of poly11a, obtained in the presence of 12 in sulfolane at $150{ }^{\circ} \mathrm{C}$, as a function of monomer conversion: $[\mathbf{1 1 a}]_{0}=0.17 \mathrm{M}$; [12 $]_{0}=11.7 \mathrm{mM}$. (B) $M_{\mathrm{n}}$ and $M_{\mathrm{w}} / M_{\mathrm{n}}$ values of poly11a, obtained in the presence of 12 in sulfolane at $150^{\circ} \mathrm{C}$, as a function of the feed ratio of 11a to 12: $[11 a]_{0}=0.17 \mathrm{M} ;[12]_{0}=8.3-$ $167 \mathrm{mM}$; conversion $=100 \%$.

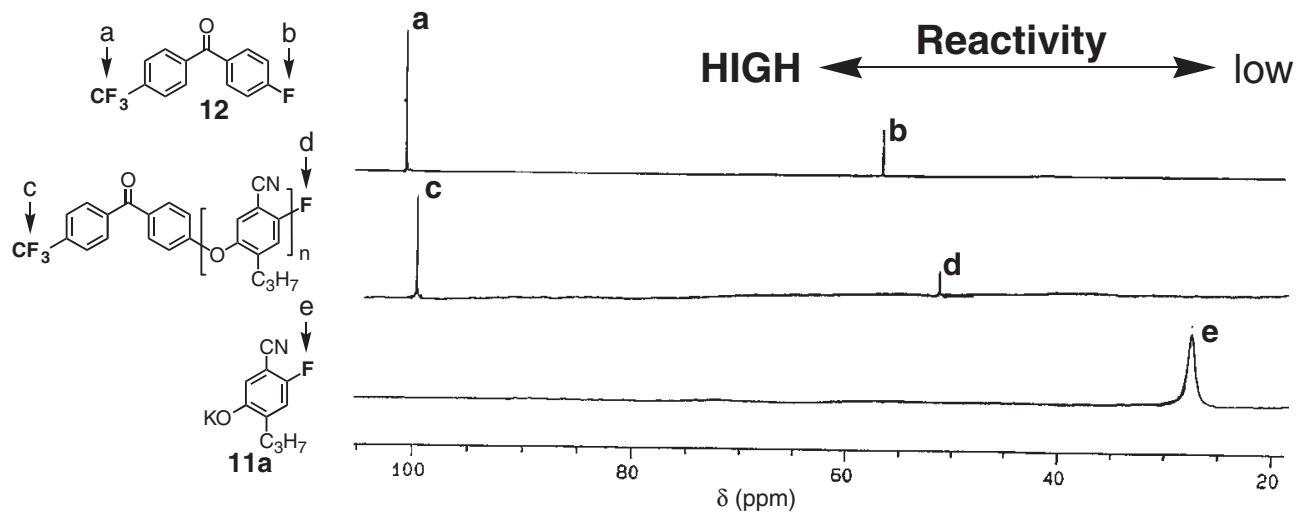

Figure 8. ${ }^{19} \mathrm{~F}$ NMR spectra of $\mathbf{1 2}$ and $\mathbf{1 1 a}$ in DMSO- $d_{6}$ and that of polymer end group in $\mathrm{CDCl}_{3}$ at $25^{\circ} \mathrm{C}$.

is ascertained to be strongly depend on the reaction solvent; sulfolane is a specific solvent for the chaingrowth polycondensation of $\mathbf{1 1 b}$.

\section{Crystallinity of Polyether Effected by Polydispersity}

We found that the polyether from 11a prepared by conventional step-growth polymerization without addition of initiator has a good solubility, whereas the polyether with a low dispersity having the initiator residue was not freely soluble in some organic solvents in which the step-growth polymer was soluble. For example, the step-growth polymer with $M_{\mathrm{n}}$ of 8500 and $M_{\mathrm{w}} / M_{\mathrm{n}}$ of 1.67 was soluble in chloroform and THF, whereas the chain-growth polymer with
$M_{\mathrm{n}}$ of more than 4000 and $M_{\mathrm{w}} / M_{\mathrm{n}}$ of 1.1 was not soluble in most of organic solvents. Furthermore, the powder X-Ray diffraction (XRD) patterns of both polymers with similar molecular weights showed that the chain-growth polymer has a higher crystallinity than the step-growth polymer (Figure 10). ${ }^{54}$ The differential scanning calorimetry (DSC) profiles of the step-growth polymer showed no peak of both the first and second heatings (Figure 11A). On the other hand, the DSC profile of the chain-growth polymer showed the endothermic peak of the first heating at $255^{\circ} \mathrm{C}$ $\left(T_{\mathrm{m}}\right)$ (Figure 11B). The complete melting sample was glassified by rapidly cool quenching to room temperature. The second heating DSC profile of the poly- 
(A)

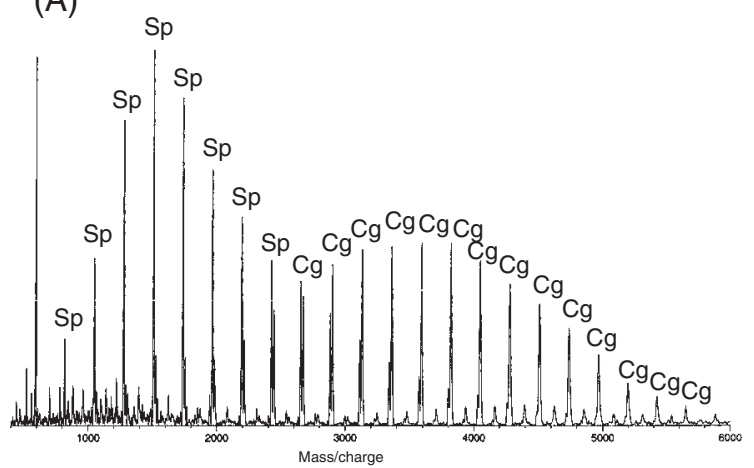<smiles>Cc1cc(Oc2ccc(C(=O)c3ccc(C(F)(F)F)cc3)cc2)ccc1C#N</smiles>

(B)

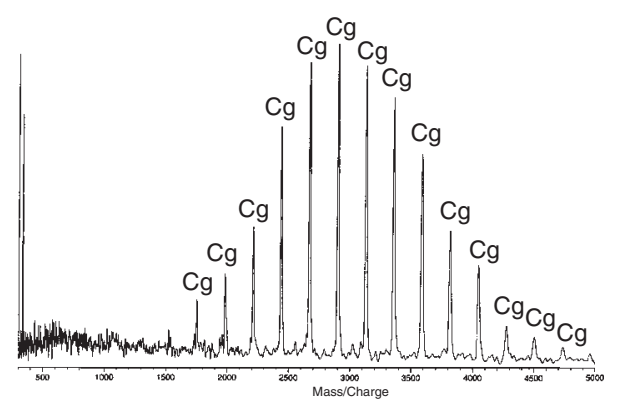

Figure 9. MALDI-TOF mass spectra of poly11b obtained in the presence of 12 at $150{ }^{\circ} \mathrm{C}:(\mathrm{A})$ in DMI $\left([\mathbf{1 1 b}]_{0} /[\mathbf{1 2}]_{0}=50\right.$, conversion $=29 \%) ;(\mathrm{B})$ in sulfolane $\left([\mathbf{1 1 b}]_{0} /[\mathbf{1 2}]_{0}=14.9\right.$, conversion $\left.=75 \%\right)$.

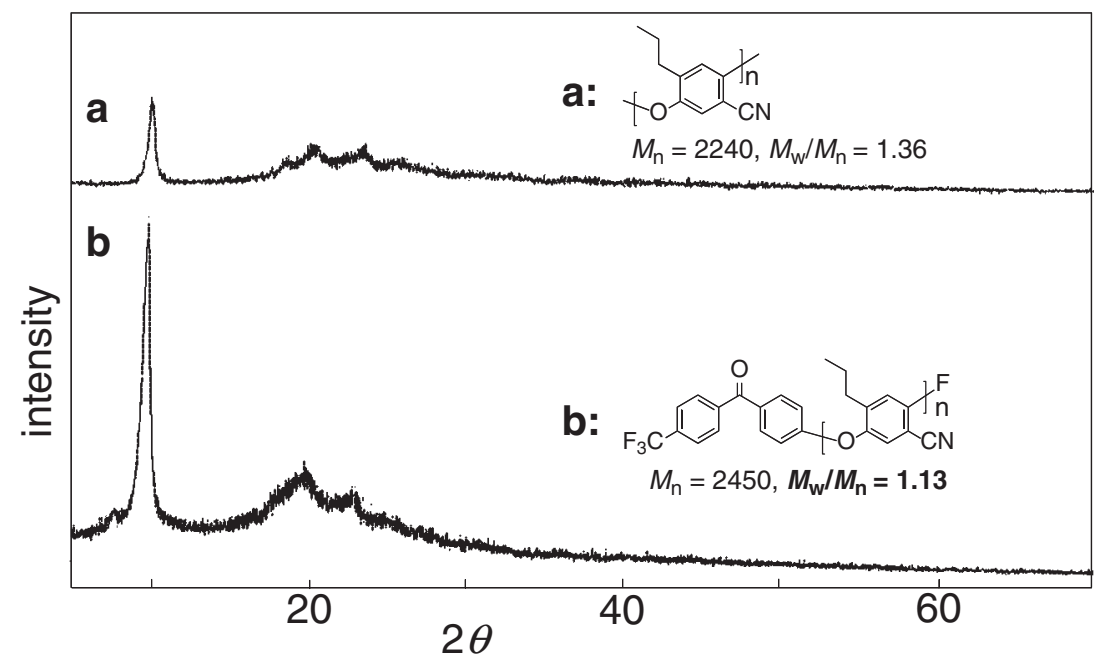

Figure 10. XRD pattern: (a) poly11a obtained by conventional polycondensation without $\mathbf{1 2}$ in sulfolane at $150^{\circ} \mathrm{C}:[11 \mathrm{a}]_{0}=0.17 \mathrm{M}$; (b) poly11a obtained in the presence of 12 at $150{ }^{\circ} \mathrm{C}$ in sulfolane: $[\mathbf{1 1 a}]_{0}=0.17 \mathrm{M} ;[\mathbf{1 2}]_{0}=11.7 \mathrm{mM}$.

mer showed the endothermic peak at $78^{\circ} \mathrm{C}\left(T_{\mathrm{g}}\right)$ and the exothermic peak at $172{ }^{\circ} \mathrm{C}$ (cold crystallization) and the endothermic peak at $255^{\circ} \mathrm{C}\left(T_{\mathrm{m}}\right) .{ }^{54}$ These results also indicate distinctly that the polymer with a low polydispersity obtained by chain-growth polycondensation possesses higher crystallinity, and implies that the crystallinity of condensation polymers could be controlled by polydispersity.

\section{POLY(ETHER SULFONE)}

The polyether synthesis in the previous section has been applied to the synthesis of well-defined poly(ether sulfone), which is one of famous engineering plastics. ${ }^{55}$ Monomer $\mathbf{1 3}$ is different from other monomers for chain-growth polycondensation in that the monomer consists of two benzene rings and that the nucleophilic site and the electrophilic site are on each benzene ring, respectively. It is then interesting whether the substituent effect of the nucleophilic site can be conveyed effectively to the electrophilic site through two benzene rings connected with the sulfonyl group.

The polymerization of $\mathbf{1 3}{ }^{56}$ with initiator $\mathbf{1 4}$ was carried out at $120^{\circ} \mathrm{C}$ in sulfolane in the presence of 18-crown-6, which would increase the electron-donating ability of the phenoxide of $\mathbf{1 3}$ by capturing potassium cation to deactivate fluorine of $\mathbf{1 3}$ more effectively. The polymerization behavior is shown in Figure 12. In the polymerization with $5 \mathrm{~mol} \%$ of $\mathbf{1 4}$, the molecular weights increased linearly with conversion and agreed with calculated values. The molecular weight distributions were about 1.3 over the whole conversion range, although they were a little broader than other polymers from chain-growth polycondensation described above. The ratios of the initiator unit $\mathrm{CF}_{3}$ to the terminal fluorine $\left(\mathrm{CF}_{3} / \mathrm{F}\right)$ kept 1.0 over the whole conversion range. These results indicate chain-growth polymerization took place. When the 
(A)

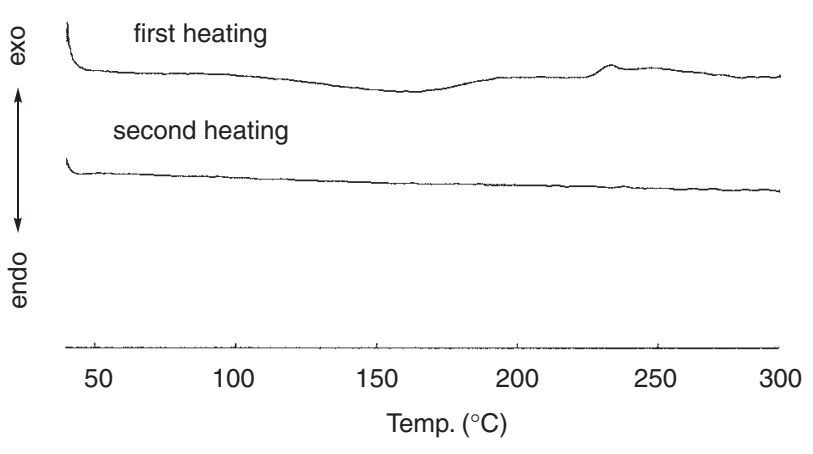

(B)

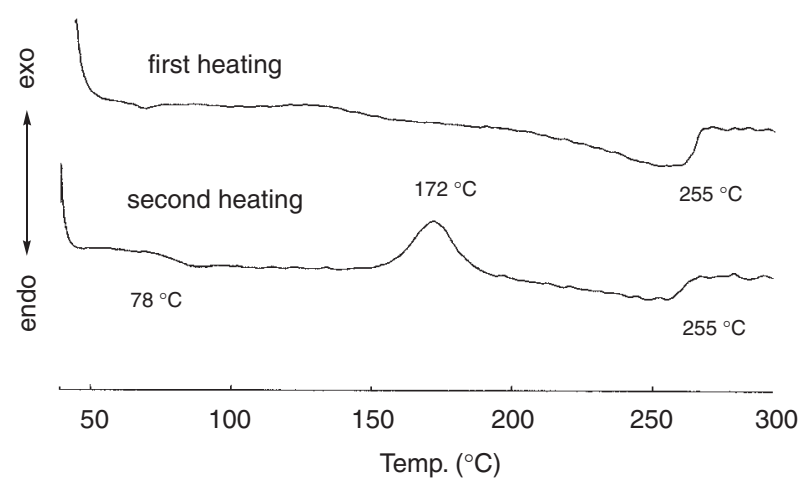

Figure 11. DSC profiles of poly11a: (A) poly11a obtained by conventional polycondensation without 12 in sulfolane at $150{ }^{\circ} \mathrm{C}$ : $[11 \mathrm{a}]_{0}=0.17 \mathrm{M}\left(M_{\mathrm{n}}=2240, M_{\mathrm{w}} / M_{\mathrm{n}}=1.36\right)$; (B) poly11a obtained in the presence of $\mathbf{1 2}$ at $150^{\circ} \mathrm{C}$ in sulfolane: [11a $]_{0}=$ $0.17 \mathrm{M} ;[\mathbf{1 2}]_{0}=11.7 \mathrm{mM}\left(M_{\mathrm{n}}=2450, M_{\mathrm{w}} / M_{\mathrm{n}}=1.13\right)$. polymerization was conducted with varying the feed ratio of monomer to initiator, the molecular weights increased in proportion to the feed ratio, but the polydispersity gradually increased. The ratios of $\mathrm{CF}_{3} / \mathrm{F}$ kept 1.0 until the feed ratio was 20 , but after that it dropped to about 0.7 . This implies that chain-growth polycondensation proceeded until the feed ratio was 20 , but after that both chain-growth and step-growth polycondensations occurred.

The contamination of step-growth polycondensation in the case of attempting to obtain higher molecular weight polymers is best accounted for by transetherification of the backbone ether linkage with monomer and/or fluoride ion as the polymer backbone becomes longer. It has been known that the transetherification takes place in these polymers containing the strong electron-withdrawing sulfonyl group. ${ }^{57-60}$ After this transetherification, the polymers having the phenoxide and fluorine on both ends are generated and conventional step-growth polycondensation sets in, resulting in broad molecular weight distribution and drop of the $\mathrm{CF}_{3} / \mathrm{F}$ ratio.

\section{POLYTHIOPHENE}

Polythiopehe has recently received much attention because it has interesting properties such as high electrical conductivity, ${ }^{61,62}$ light emitting ability ${ }^{63}$ fieldeffect mobility, ${ }^{64,65}$ and so on. The Ni-catalyzed regiocontrolled synthesis of poly(3-alkylthiophene) has been developed by McCullough ${ }^{66-71}$ and Rieke ${ }^{72-74}$

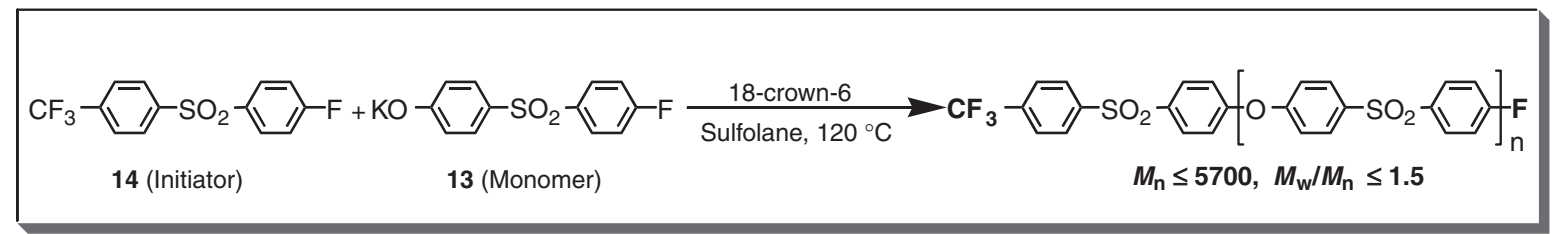

\section{(A)}
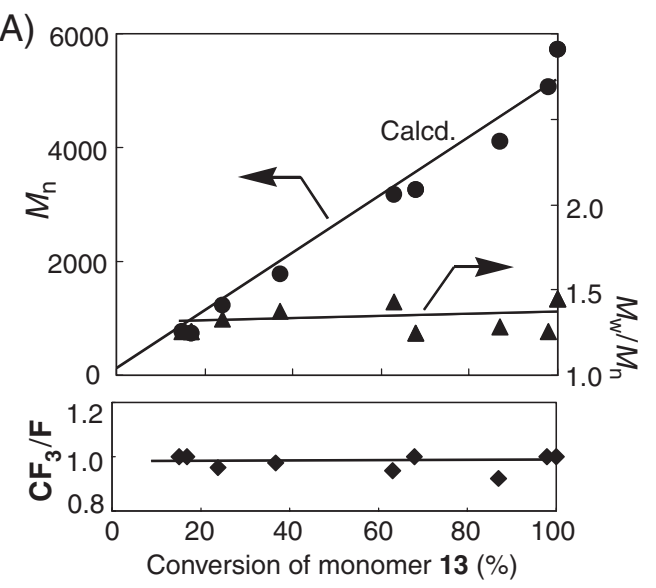

(B)

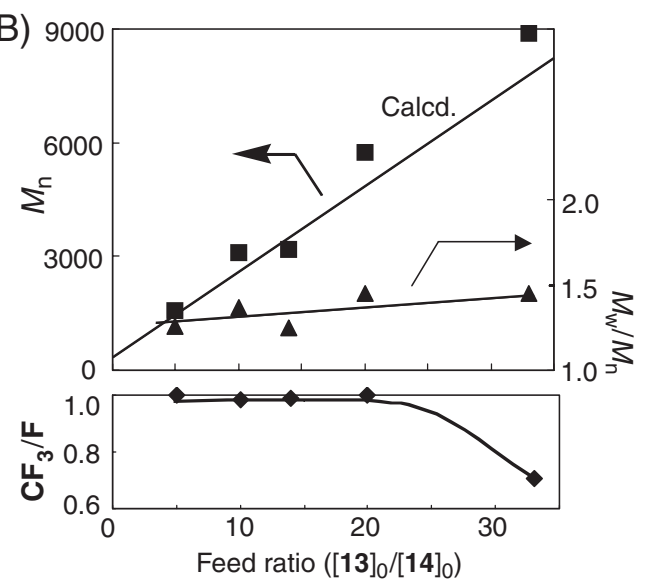

Figure 12. (A) $M_{\mathrm{n}}$ and $M_{\mathrm{w}} / M_{\mathrm{n}}$ values of poly13 and the ratios of initiator unit to end group $\left(\mathrm{CF}_{3} / \mathrm{F}\right)$ in poly13, obtained in the presence of $\mathbf{1 4}$ and 18-crown- 6 in sulfolane at $120^{\circ} \mathrm{C}$, as a function of monomer conversion: $[\mathbf{1 3}]_{0}=0.17 \mathrm{M} ;[\mathbf{1 4}]_{0}=8.3 \mathrm{mM}$; $[18 \text {-crown-6 }]_{0}=$ 0.17 M. (B) $M_{\mathrm{n}}$ and $M_{\mathrm{w}} / M_{\mathrm{n}}$ values of poly13 and the ratios of initiator unit to end group $\left(\mathrm{CF}_{3} / \mathrm{F}\right)$ in poly13, obtained in the presence of $\mathbf{1 4}$ in sulfolane at $120^{\circ} \mathrm{C}$, as a function of the feed ratio of $\mathbf{1 3}$ to $\mathbf{1 4}:[\mathbf{1 3}]_{0}=0.17 \mathrm{M} ;[\mathbf{1 4}]_{0}=5.0-33 \mathrm{mM}$; conversion $=100 \%$. 
groups, but those polymers have broad molecular weight distributions, which are believed to be produced via typical step-growth polycondensation. On the basis of our approach to chain-growth polycondensation, however, we think that monomer $\mathbf{1 5}$ has an ability to undergo chain-growth polycondensation. Thus, the bromine of $\mathbf{1 5}$ is deactivated by anionic charge on the carbon atom of thiophene ring adjacent to magnesium, and then the bromine gets more reactive as $\mathbf{1 5}$ has reacted with the polymer end group because the anionic charge converted into conjugated covalent bond (Scheme 17).

The polymerization of $\mathbf{1 5}$ was carried out with a catalytic amount of $\mathrm{Ni}(\mathrm{dppp}) \mathrm{Cl}_{2}(\mathrm{dppp}=1,3$-bis- (diphenylphosphino)propane) at room temperature. ${ }^{75}$ The GPC elution curve of polymer obtained showed a narrow molecular weight distribution, although it has a small shoulder in the higher molecular weight region. Furthermore, the molecular weights were found to increase in proportion to conversion while retaining low polydispersities (Figure 13A). Therefore, it turns out that this condensation also proceeds in a chain-growth polymerization manner.

Since an initiator was not added in this polymerization, one might think that it is impossible to control molecular weight of polymer. Fortunately, however, the molecular weight could be controlled by the amount of $\mathrm{Ni}(\mathrm{dppp}) \mathrm{Cl}_{2}$. Figure 13B shows the plot
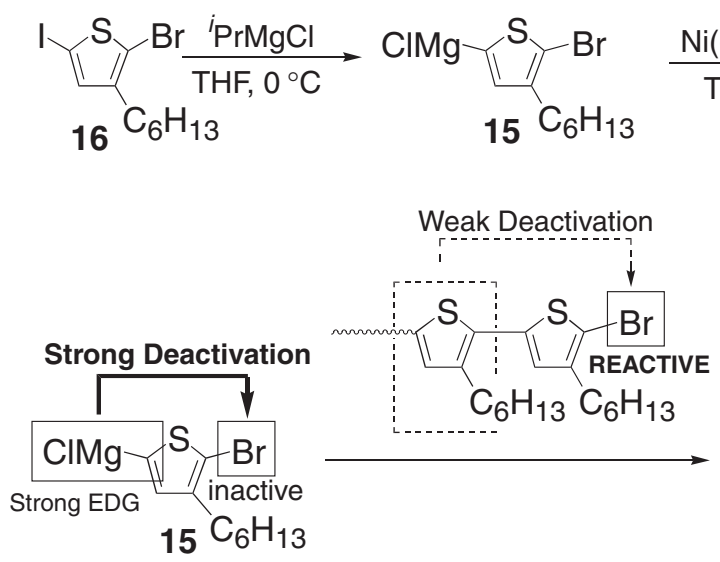

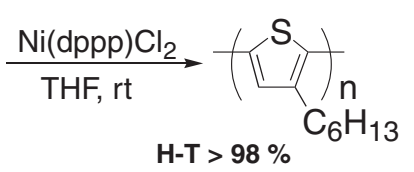

$M_{\mathrm{n}} \leq 30000, M_{\mathrm{w}} / M_{\mathrm{n}} \leq 1.3$

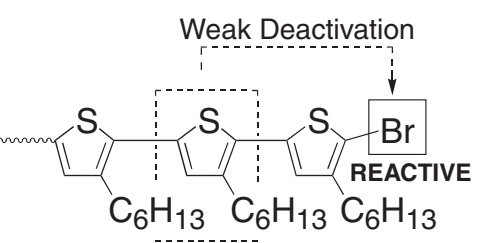

Scheme 17.

(A)

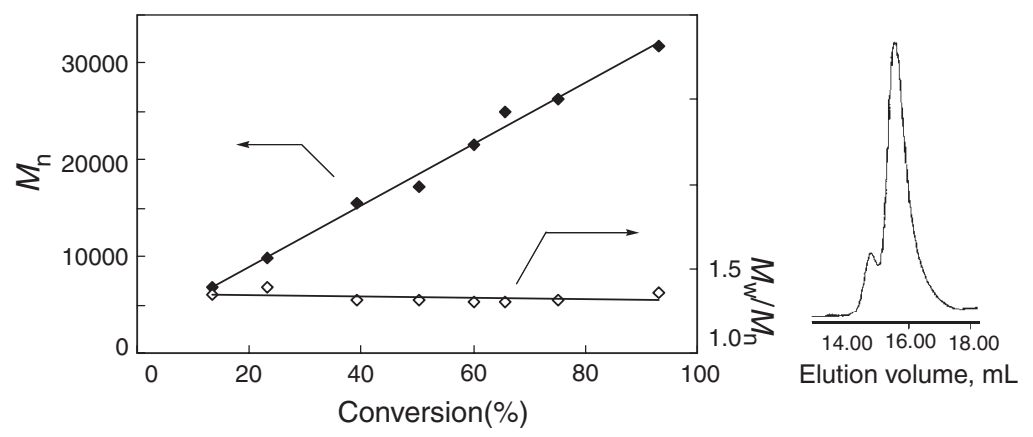

(B)

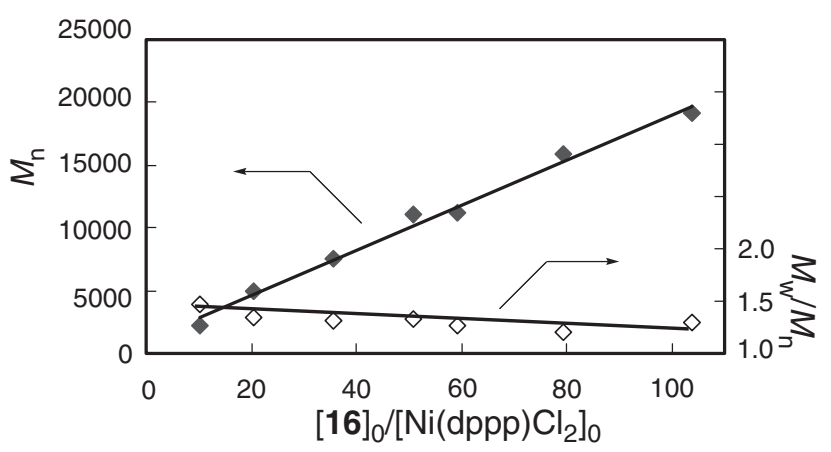

Figure 13. (A) $M_{\mathrm{n}}$ and $M_{\mathrm{w}} / M_{\mathrm{n}}$ values of poly 15, obtained with $0.4 \mathrm{~mol} \%$ of $\mathrm{Ni}(\mathrm{dppp}) \mathrm{Cl}_{2}$ in $\mathrm{THF}$ at $25^{\circ} \mathrm{C}$, as a function of monomer conversion: $[\mathbf{1 5}]_{0}=0.12 \mathrm{M}$. (B) $M_{\mathrm{n}}$ and $M_{\mathrm{w}} / M_{\mathrm{n}}$ values of poly 15 , obtained with $\mathrm{Ni}(\mathrm{dppp}) \mathrm{Cl}_{2}$ in $\mathrm{THF}$ at $25^{\circ} \mathrm{C}$, as a function of the feed ratio of 15 to $\mathrm{Ni}(\mathrm{dppp}) \mathrm{Cl}_{2}:[\mathbf{1 5}]_{0}=0.12 \mathrm{M}$; $\left[\mathrm{Ni}(\mathrm{dppp}) \mathrm{Cl}_{2}\right]_{0}=1.1-11.8 \mathrm{mM}$; conversion $=86-93 \%$. 
of the molecular weights against the feed ratio of monomer to Ni-catalyst. The molecular weights increased linearly with the feed ratio, and the polydispersities are always below 1.3. The exact polymerization mechanism is not clear at present time, but the dimer of $\mathbf{1 5}$, which is formed when zero-valent nickel is generated from $\mathrm{Ni}(\mathrm{dppp}) \mathrm{Cl}_{2}$ and 2 equiv of $\mathbf{1 5}$, may initiate the chain-growth polymerization of $\mathbf{1 5}$.

\section{CHAIN-GROWTH POLYCONDENSATION IN BIPHASE}

As mentioned in the Introduction, an important thing for successful chain-growth polycondensation is to prevent the reaction of monomers with each other leading to step-growth polycondensations. Therefore, the polymerization of solid monomers dispersed in organic solvent with a phase transfer catalyst (PTC) would be an attractive route to chain-growth polycondensation, because solid monomers do not react with each other and the monomer transferred to organic solvent with PTC would react with an initiator and the polymer end group in organic solvent. We investigated the polycondensation of solid monomer, potassium 4-bromomethyl-2-octyloxybenzoate 17, with 18crown-6 as a PTC in acetone in the presence of 4-nitrobenzyl bromide $\mathbf{1 8}$ as an initiator (Scheme 18). ${ }^{76}$

We first optimized the amount of 18-crown-6 for this polymerization. The polymerization of $\mathbf{1 7}$ was carried out in the presence of $10 \mathrm{~mol} \%$ of $\mathbf{1 8}$ at various amounts of 18-crown-6 at room temperature for 24 $48 \mathrm{~h}$ (conversion $=100 \%)$ (Table II). Equimolar amounts of 18-crown-6 and $\mathbf{1 8}$ were found to yield polyester with the narrowest polydispersity.

To elucidate whether chain-growth polymerization takes place in this polycondensation, the polymer molecular weights, polydispersities, and the ratios of initiator unit to end group in polymer were plotted against monomer conversion (Figure 14A). Furthermore, the polymerization of $\mathbf{1 7}$ with $\mathbf{1 8}$ was also carried out in the presence of tetrabutylammonium bro-
Table II. Effect of the amount of 18-crown-6 on polymerization of $\mathbf{1 7}$ in the presence of $10 \mathrm{~mol} \%$ of $\mathbf{1 8}^{\mathrm{a}}$

\begin{tabular}{ccc}
\hline $\begin{array}{c}\text { 18-crown-6 } \\
\text { (mol\%) }\end{array}$ & $M_{\mathrm{n}}{ }^{\mathrm{b}}$ & $M_{\mathrm{w}} / M_{\mathrm{n}}{ }^{\mathrm{b}}$ \\
\hline 2 & 2900 & 1.49 \\
5 & 2800 & 1.45 \\
7 & 2700 & 1.47 \\
10 & 2400 & 1.36 \\
15 & 2500 & 1.45 \\
30 & 2500 & 1.57 \\
100 & 2500 & 2.13 \\
\hline
\end{tabular}

${ }^{\text {a }}$ Polymerization of $\mathbf{1 7}$ was conducted in acetone $\left([\mathbf{1 7}]_{0}=0.33 \mathrm{M}\right)$ at $25^{\circ} \mathrm{C}$ for $24-48 \mathrm{~h}$ (conversion $=100 \%)$. ${ }^{\mathrm{b}}$ Determined by GPC based on polystyrene standards using THF as solvent.

mide as a PTC in water-dichloromethane as a typical biphasic polymerization to compare both polymerization behaviors (Figure 14B). ${ }^{77}$ In the solid-liquid biphasic polymerization, the molecular weights increased in proportion to conversion, and the $M_{\mathrm{w}} / M_{\mathrm{n}}$ ratios were less than 1.3 over the whole conversion range. The ratios of initiator unit to end group were constantly about 1.0 irrespective of conversion (Figure 14A). These data indicate chain-growth polymerization. On the other hand, in the liquid-liquid biphasic polymerization, the molecular weights did not increase much at low conversion of monomer and were accelerated at high conversion, and the $M_{\mathrm{w}} / M_{\mathrm{n}}$ ratios gradually increased to 1.5 . The ratios of initiator unit to end group kept less than 1.0 during polymerization and reached 1.0 in the last stage (Figure 14B). This polymerization behavior shows typical stepgrowth polymerization. Consequently, this study demonstrates that solid-liquid biphasic polymerization can alter conventional step-growth polycondensation in liquid-liquid biphase into chain-growth polycondensation, even though the same monomer is used.

Similar chain-growth polycondensation of solid monomer in acetone was attained with tetrabutylammonium iodide instead of crown ether. ${ }^{78}$
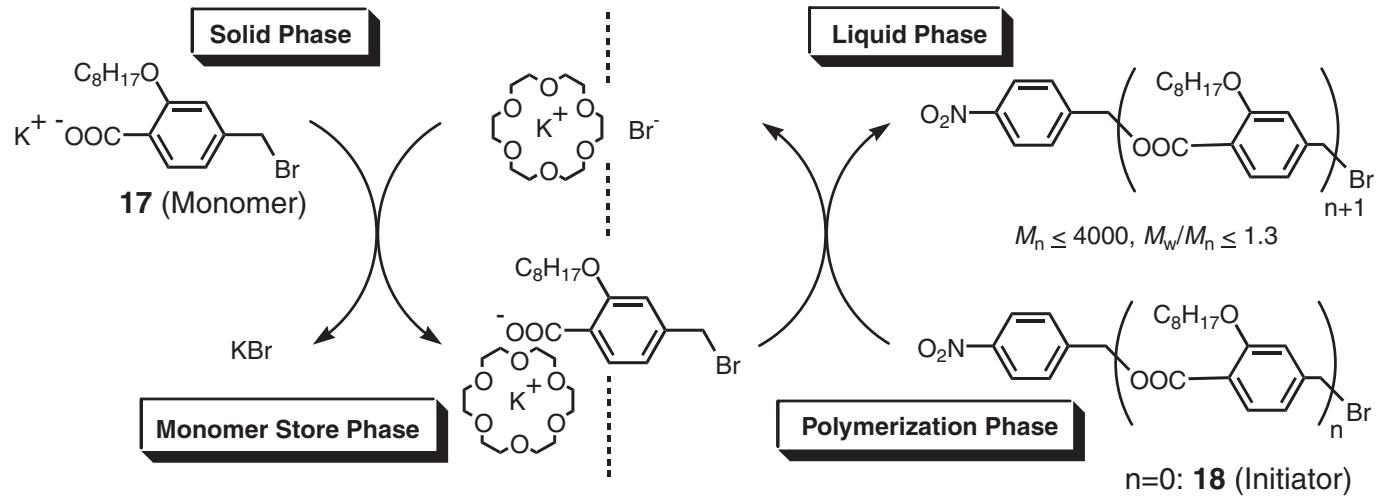

Scheme 18. 
(A)
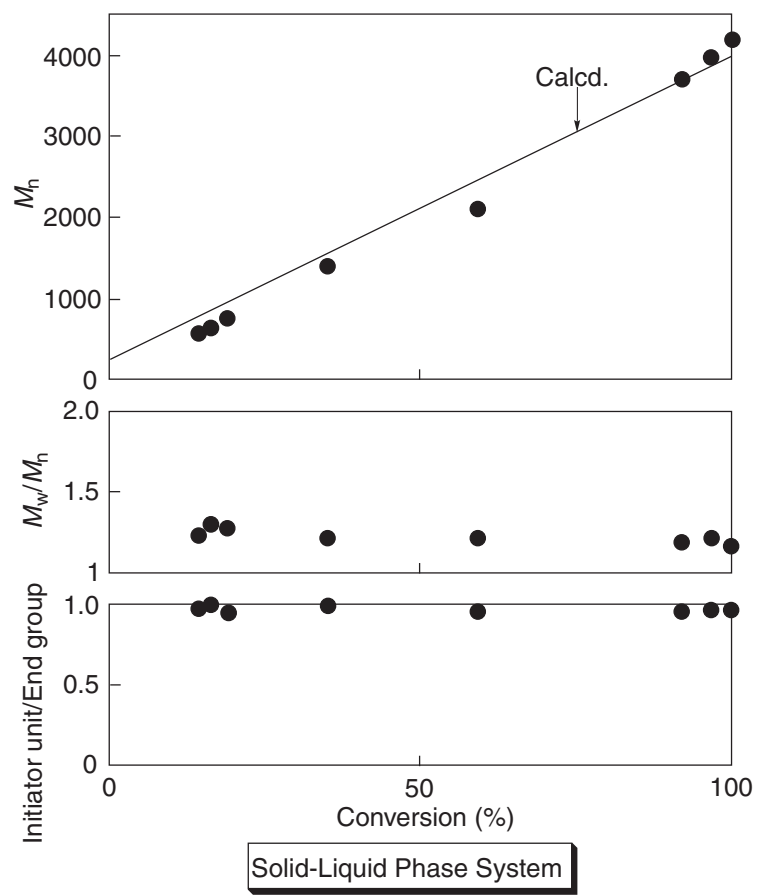

(B)
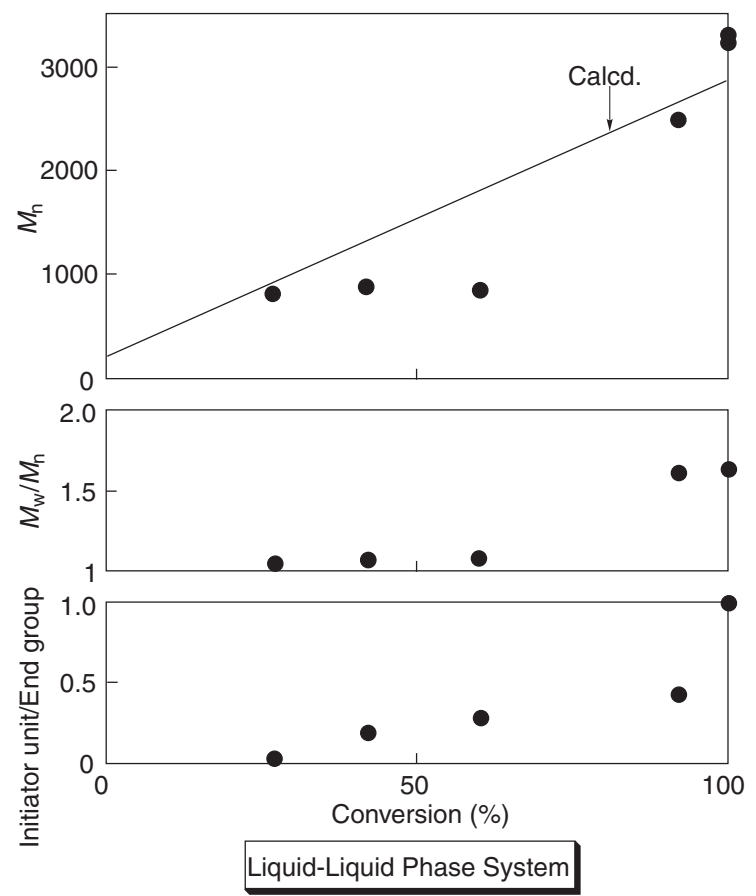

Figure 14. $M_{\mathrm{n}}$ and $M_{\mathrm{w}} / M_{\mathrm{n}}$ values of poly17 and the ratios of initiator unit to end group in poly17, obtained in the presence of 18, as a function of monomer conversion: (A) in solid-liquid phase with $7 \mathrm{~mol} \%$ of $\mathbf{1 8}$ in acetone at $25^{\circ} \mathrm{C}\left([\mathbf{1 7}]_{0}=0.33 \mathrm{M} ;[\mathbf{1 8}]_{0}=[18 \text {-crown-6 }]_{0}\right.$ $=0.023 \mathrm{M})$; (B) in liquid-liquid phase with $10 \mathrm{~mol} \%$ of 18 and $10 \mathrm{~mol} \%$ of TBAB in water $(1.0 \mathrm{~mL})$ and dichloromethane $(0.5 \mathrm{~mL})$ at $25^{\circ} \mathrm{C}$ (0.5 mmol of 17).

\section{CONCLUDING REMARKS}

We have described that the condensation polymers in Scheme 3 can be obtained in a controlled fashion: defined molecular weights and low polydispersities by two approaches: (1) activation of polymer end group by substituent effects changed between monomer and polymer, and (2) phase-transfer polymerization in biphase composed of monomer store phase and polymerization phase. These polycondensations proceed in a chain-growth polymerization manner like living polymerization. Stable polymer end groups of these condensation polymers enable us to synthesize well-defined architectures such as di- and triblock copolymers of different condensation polymers and of condensation polymers and conventional polymers. Furthermore, simple structures of initiators also facilitate the synthesis of block copolymers, star polymers, and graft polymers from conventional polymers. For example, the chain-growth polycondensation took place from the polystyrene containing the phenyl ester moieties to yield polystyrene-graft-aromatic polyamide. ${ }^{79}$ Research of self-assembly of these architectures containing condensation polymers with low polydispersities will open a new field of supramolecular chemistry of polymers, because a huge amount of studies about self-assembly of block copolymers have being done only by using coil polymers, and because condensation polymers are arranged differently by virtue of strong intermolecular forces. For example, the block copolymers of styrene and condensation polymers with even a broad molecular weight distribution self-organize into a variety kinds of aggregates. ${ }^{80,81}$ Our investigation of self-assembly of condensation polymer architectures are in progress, as well as development of more kinds of approaches and monomers that undergo chain-growth polycondensation.

Acknowledgment. The authors acknowledge Dr. Kim Sunwook, Dr. Aya Tanatani, Dr. Yukimitsu Suzuki, and other members of the research group of Kanagawa University. Prof. Kazuo Tajima (Kanagawa Univ.), Prof. Isao Azumaya (Kitasato Univ.), Dr. Ren-Hua Jin (Kawamura Inst. of Chem. Res.), Prof. Toshikazu Takata (Tokyo Inst. of Technol.), Prof. Nobuhiro Kihara (Osaka Prefecture Univ.), and Prof. Junji Watanabe (Tokyo Inst. of Technol.) are acknowledged for their continuous collaboration and invaluable discussions. This work was financially supported by the Japan Science and Technology Agency (JST) and by Grant-in-Aids from the Ministry of Education, Culture, Sports, Science and Technology of Japan. 


\section{REFERENCES}

1. H. Weissbach and S. Pestka, "Molecular Mechanism of Protein Biosynthesis," Academic Press, New York, N.Y., 1977.

2. E. Bermek, "Mechanism of Protein Synthesis. StructureFunction Relations, Control Mechanisms, and Evolutionary Aspects," Springer-Verlag, New York, N.Y., 1985.

3. A. Kornberg, Science, 131, 1503 (1960).

4. A. Travers, Nature, 263, 641 (1976).

5. M. Chamberlin, in "The Enzymes," P. D. Boyer, Ed., Academic Press, New York, N.Y., 1982, vol 15, p 61.

6. D. R. Light and M. S. Dennis, J. Biol. Chem., 264, 18589 (1989).

7. D. R. Light, R. A. Lazarus, and M. S. Dennis, J. Biol. Chem., 264, 18598 (1989).

8. M. S. Dennis and D. R. Light, J. Biol. Chem., 264, 18608 (1989).

9. R. W. Lenz, C. E. Handlovits, and H. A. Smith, J. Polym. Sci., 58, 351 (1962).

10. A. B. Newton and J. B. Rose, Polymer, 13, 465 (1972).

11. D. B. Hibbert and J. P. B. Sandall, J. Chem. Soc. Perkin Trans. II, 1988, 1739.

12. D. R. Robello, A. Ulman, and E. J. Urankar, Macromolecules, 26, 6718 (1993).

13. W. Koch, W. Risse, and W. Heitz, Makromol. Chem. Suppl., 12, 105 (1985).

14. W. Risse and W. Heitz, Makromol. Chem., 186, 1835 (1985).

15. V. Percec and J. H. Wang, J. Polym. Sci., Part A: Polym. Chem., 29, 63 (1991).

16. V. Perece and T. D. Shaffer, J. Polym. Sci., Part C: Polym. Lett., 24, 439 (1986).

17. V. Percec and J. H. Wang, Polym. Bull., 24, 493 (1990).

18. C. H. Honeyman, I. Manners, C. T. Morrissey, and H. R. Allcock, J. Am. Chem. Soc., 117, 7035 (1995).

19. H. R. Allcock, C. A. Crane, C. T. Morrissey, J. M. Nelson, S. D. Reeves, C. H. Honeyman, and I. Manners, Macromolecules, 29, 7740 (1996).

20. H. R. Allcock, J. M. Nelson, S. D. Reeves, C. H. Honeyman, and I. Manners, Macromolecules, 30, 50 (1997).

21. H. R. Allcock, S. D. Reeves, C. R. Denus, and C. A. Crane, Macromolecules, 34, 748 (2001).

22. K. J. Shea, H. Zhu, J. R. Walker, M. M. Paz, and J. Greaves, J. Am. Chem. Soc., 119, 9049 (1997).

23. K. J. Shea, B. B. Busch, and M. M. Paz, Angew. Chem. Int. Ed., 38, 1391 (1998)

24. K. J. Shea, S. Y. Lee, and B. B. Busch, J. Org. Chem., 63, 5746 (1998).

25. K. J. Shea, Chem. Eur. J., 6, 1113 (2000).

26. K. J. Shea and C. E. Wagner, Org. Lett., 3, 3063 (2001).

27. K. J. Shea, B. B. Busch, M. M. Paz, C. L. Straiger, J. M. Stoddard, J. R. Walker, X. Zhou, and H. Zhu, J. Am. Chem. Soc., 124, 3636 (2002)

28. V. Percec, in "ACS Symposium Series," American Chemical Society, Washington, D.C., 1987, vol. 326, p. 96.

29. V. Percec, T. D. Shaffer, and H. Nava, J. Polym. Sci., Part C: Polym. Lett., 22, 637 (1984).

30. T. D. Shaffer and V. Percec, J. Polym. Sci., Part A: Polym.
Chem., 24, 451 (1986).

31. T. D. Shaffer and M. C. Kramer, Makromol. Chem., 191, 71 (1990).

32. K. Miyatake, A. R. Hlil, and A. S. Hay, Macromolecules, 34, 4288 (2001).

33. T. Yokozawa, T. Asai, R. Sugi, S. Ishigooka, and S. Hiraoka, J. Am. Chem. Soc., 122, 8313 (2000).

34. Y. Shibasaki, T. Araki, M. Okazaki, and M. Ueda, Polym. J., 34, 261 (2002).

35. T. Yokozawa, R. Sugi, T. Asai, and A. Yokoyama, Chem. Lett., in press.

36. T. Yokozawa, M. Ogawa, A. Sekino, R. Sugi, and A. Yokoyama, J. Am. Chem. Soc., 124, 15158 (2002).

37. Y. Izawa, S. Hiraoka, and T. Yokozawa, Polym. Prepr. Jpn., 50, 215 (2001).

38. R. Sugi, A. Yokoyama, and T. Yokozawa, Macromol. Rapid Commun., 24, 1085 (2003).

39. S. Kim, Y. Kakuda, A. Yokoyama, and T. Yokozawa, Polym. Prepr. Jpn., 52, 286 (2003).

40. R. Sugi, Y. Hitaka, A. Sekino, A. Yokoyama, and T. Yokozawa, J. Polym. Sci., Part A: Polym. Chem., 41, 1341 (2003).

41. A. Sekino, A. Yokoyama, and T. Yokozawa, Polym. Prepr. Jpn., 51, 1428 (2002).

42. N. Hasenaka, R. Sugi, A. Yokoyama, and T. Yokozawa, Polym. Prepr. Jpn., 52, 287 (2003).

43. T. Urushima, A. Sekino, A. Yokoyama, and T. Yokozawa, Polym. Prepr. Jpn., 52, 288 (2003).

44. T. Yokozawa and H. Shimura, J. Polym. Sci., Part A: Polym. Chem., 37, 2607 (1999).

45. M. Ueda, A. Sato, and Y. Imai, J. Polym. Sci., Part A: Polym. Chem., 15, 2731 (1977).

46. T. Yokozawa and S. Horio, Polym. J., 28, 633 (1996).

47. A. Yokoyama, K. Iwashita, K. Hirabayashi, K. Aiyama, and T. Yokozawa, Macromolecules, 36, 4328 (2003).

48. K. Iwashita, A. Yokoyama, and T. Yokozawa, Polym. Prepr. Jpn., 51, 1267 (2002).

49. K. Iwashita, A. Yokoyama, and T. Yokozawa, Polym. Prepr. Jpn., 52, 235 (2003).

50. T. Yokozawa, Y. Suzuki, and S. Hiraoka, J. Am. Chem. Soc., 123, 9902 (2001).

51. The polyether from potassium 3-cyano-4-fluoro-2-propylphenolate is more soluble than the polyether from 11a, and the molecular weight can be controlled until 10000 with low polydispersites, see: Y. Suzuki, A. Yokoyama, and T. Yokozawa, Polym. Prepr. Jpn., 52, 229 (2003).

52. A. E. Lozano, M. L. Jimeno, J. Abajo, and J. G. Camp, Macromolecules, 27, 7164 (1994).

53. Y. Suzuki, S. Hiraoka, A. Yokoyama, and T. Yokozawa, J. Polym. Sci., Part A: Polym. Chem., in press.

54. Y. Suzuki, S. Hiraoka, A. Yokoyama, and T. Yokozawa, Macromolecules, 36, 4756 (2003).

55. T. Yokozawa, T. Taniguchi, Y. Suzuki, and A. Yokoyama, J. Polym. Sci., Part A: Polym. Chem., 40, 3460 (2002).

56. For conventional polycondensation of 13, see: R. N. Johnson, A. G. Farnham, R. A. Clendinning, W. F. Hale, and C. N. Merriam, J. Polym. Sci., Part A-1: Polym. Chem., 5, 2375 (1967).

57. Y. Wang, K. P. Chan, and A. S. Hay, J. Polym. Sci., Part A: 
Polym. Chem., 34, 375 (1996).

58. V. Carlier, B. Jamble, J. Devaux, R. Legras, and P. T. McGrail, Polymer, 34, 167 (1993).

59. A. Ben-Haida, I. Baxter, H. M. Colquhoun, P. Hodge, F. H. Kohnke, and D. J. Williams, Chem. Commun., 1997, 1533.

60. I. Baxter, A. Ben-Haida, H. M. Colquhoun, P. Hodge, F. H. Kohnke, and D. J. Williams, Chem. Commun., 1998, 2213.

61. J. Roncali, Chem. Rev., 97, 173 (1997).

62. R. D. McCullough, Adv. Mater., 10, 93 (1998).

63. F. Chen, P. G. Mehta, L. Takiff, and R. D. McCullough, J. Mater. Chem., 6, 1763 (1996).

64. H. Sirringhaus, N. Tessler, and R. H. Friend, Science, 280, 1741 (1998),

65. H. Sirringhaus, P. J. Brown, R. H. Friend, M. M. Neilsen, K. Bechgaard, B. M. W. Langeveld-Voss, A. J. H. Spiering, R. A. J. Jansscen, E. W. Meijer, P. Herwig, and D. M. de Leeuw, Nature, 401, 685 (1999).

66. R. D. McCullough and R. D. Lowe, J. Chem. Soc., Chem. Commun., 1992, 70.

67. R. D. McCullough, R. D. Lowe, M. Jayaraman, and D. L. Anderson, J. Org. Chem., 58, 904 (1993).

68. R. S. Loewe, S. M. Kheronsky, and R. D. McCullough, Adv. Mater., 11, 250 (1999).

69. R. S. Loewe, P. C. Ewbank, J. Liu, L. Zhai, and R. D.
McCullough, Macromolecules, 34, 4324 (2001).

70. J. Liu, E. Sheina, T. Kowaleski, and R. D. McCullough, Angew. Chem., Int. Ed., 41, 329 (2002).

71. J. Liu and R. D. McCullough, Macromolecules, 35, 9882 (2002).

72. T.-A. Chen and R. D. Rieke, J. Am. Chem. Soc., 114, 10087 (1992).

73. T.-A. Chen, R. A. O'Brien and R. D. Rieke, Macromolecules, 26, 3462 (1993).

74. T.-A. Chen, X. Wu, and R. D. Rieke, J. Am. Chem. Soc., 117, 233 (1995).

75. A. Yokoyama, R. Miyakoshi, and T. Yokozawa, Macromolecules, in press.

76. T. Yokozawa and H. Suzuki, J. Am. Chem. Soc., 121, 11573 (1999).

77. N. Hiyama, H. Suzuki and T. Yokozawa, Polym. Prepr. Jpn., 48, 307 (1999).

78. T. Yokozawa, D. Maeda, N. Hiyama, and S. Hiraoka, Macromol. Chem. Phys., 202, 2181 (2001).

79. M. Iwasaki, A. Yokoyama, and T. Yokozawa, Polym. Prepr. Jpn., 51, 1265 (2002).

80. S. A. Jenekhe and X. L. Chen, Science, 279, 1903 (1998).

81. S. A. Jenekhe and X. L. Chen, Science, 283, 372 (1999).

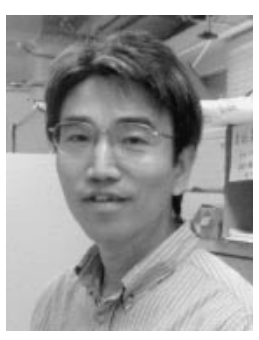

Tsutomu Yokozawa was born in Chiba in 1957. He received Bachelor and Master degrees in chemistry of organic synthesis from Tokyo Institute of Technology, Japan in 1981 and 1983, respectively, and received his Ph.D. degree from Tokyo Institute of Technology, Japan in 1987 on study of synthon approach to fluorine-containing compounds. In 1985, he had already started an academic career in the Research Laboratory of Resources Utilization, Tokyo Institute of Technology as a Research Associate, and was promoted to Assistant Professor in 1988. He joined the Department of Applied Chemistry, Kanagawa University as a Lecturer in 1991, and was promoted to Associate Professor in 1993. During 1997-1998, he worked on supramolecular chemistry as a visiting scientist at the University of Illinois at Urbana-Champaign with Professor Jeffrey S. Moore. He was promoted to Full Professor in 1999. $\mathrm{He}$ is also a researcher for PRESTO, JST in the research area of Synthesis and Control during 2001-2004. His research interest covers controlled synthesis of polymers, supramolecular chemistry of polymers, dynamic covalent chemistry, as well as synthetic organic chemistry.

Akihiro Yokoyama was born in Hokkaido in 1969. He received Bachelor and Master degree of pharmaceutical science from the University of Tokyo, Japan in 1992 and 1994, respectively, and received his Ph.D. degree of pharmaceutical science from the University of Tokyo, Japan in 1997 on study of dicationic superelectrophiles. He did postdoctoral research with Professor Koichi Shudo at the same department (1997-1998), with Professor Kazuhiko Mizuno at Osaka Prefecture University, Japan (1998-2000), and with Professor Keisuke Suzuki at Tokyo Institute of Technology, Japan (2000-2001). In 2001, he joined the Department of Applied Chemistry, Kanagawa University as a Research Associate. His main research interest is synthesis of polymers and supermolecules with well-defined three-dimensional structures. 